\title{
LA COMERCIALIZACIÓN DE LAS RENTAS AGRARIAS EN LA GALICIA DEL ANTIGUO RÉGIMEN'
}

\author{
Pegerto Saavedra \\ Universidade de Santiago de Compostela
}

\begin{abstract}
Resumen. En la Galicia del Antiguo Régimen, las instituciones eclesiásticas, la nobleza titulada y la hidalguía percibían ingentes cantidades de rentas de cereales y vino en concepto de foros, arriendos y diezmos, fundamentalmente. Tales excedentes podrían abastecer una ciudad de 200.000 habitantes, pero en Galicia la población que vivía en núcleos de más de 1.000 no sumaba 60.000 personas en 1750 . Si los mercados urbanos no podían absorber el grueso de las rentas hay que preguntarse por el destino de éstas, y al respecto los libros de cuentas de monasterios y casas hidalgas ponen de manifiesto que una cosa era la teoría y otra la práctica, dado que muchas cargas fijadas en especie se satisfacían en dinero, lo que significa que los campesinos compraban una parte de su propia cosecha, debiendo para ello participar en el mercado de productos o de mano de obra.
\end{abstract}

Palabras clave: Rentas agrarias, mercado cerealero, monasterios, hidalguía, economía campesina, Galicia, Antiguo Régimen.

Abstract. In the Galicia of the Old Regime, the ecclesiastical institutions, the titled nobility and the inferior nobility received important amounts of cereals and wine rents for foros, leasings and tithes. These excesses could supply a city of 200.000 inhabitants, but in Galicia the population that lived in localities of more than 1000 inhabitants did not surpassed 60.000 people in 1750 . If the urban markets could not absorb the rents, which was its destiny? The accounts books of monasteries and hidalgos families show that a thing was the theory and another one the practica, since many loads fixed to species were satisfied in money. This

1 Trabajo realizado en el marco del proyecto de Investigación HUM2005-06645/HIST., financiado por la Dirección General de Investigación del Ministerio de Educación y Ciencia. 
means that the farmers bought a part of their own harvest for which they had to participate in the market of products or manual labor.

Keywords: agrarian rents, cereal market, monasteries, inferior nobility, economy farmer, Galicia, Old Regime.

LA AGRICULTURA gallega del Antiguo Régimen generaba una enorme cantidad de excedentes, que permitían el sostenimiento de poderosas instituciones eclesiásticas regulares y seculares, de familias de la aristocracia, de miles de casas hidalgas y también de rectores parroquiales que llevaban en general un buen pasar, alcanzando algunos de ellos unos ingresos comparables a los de un pequeño mayorazgo. Más de un viajero se sorprendió ante la riqueza de unos monasterios asentados en un territorio en el que los campesinos vivían tan pobremente.

Se trata, desde luego, de "excedentes compulsivos", destinados al pago de rentas forales y de arriendos, de foros, diezmos, primicias, derechos de señorío y de voto de Santiago, siendo los foros y diezmos los capítulos fundamentales (junto a los arriendos en la Galicia cantábrica) ${ }^{3}$. Por las investigaciones que han venido realizando en los últimos años sobre la economía de algunas instituciones eclesiásticas y de casas hidalgas, y por las que yo mismo tengo prácticamente concluidas sobre los monasterios cistercienses y varios pazos, cabe afirmar que de dos tercios a tres cuartas partes de las rentas satisfechas por los campesinos se destinaban por sus perceptores a la venta ${ }^{4}$. Así sucedía, por ejemplo, en los casos de los monasterios de Monfero y Oseira. Si se tiene en cuenta que a mediados del siglo XVIII, de acuerdo con los resúmenes generales del catastro de Ensenada, las cargas diversas pagadas por los cultivadores ascenderían a un millón aproximado de hls. de cereales y vino, puede concluirse que saldrían, en teoría,

2 En expresión de A. Eiras Roel en "Tres problemas de historia rural”, prólogo, publicado como separata, a RODRÍGUEZ FERREIRO, H.: La tierra de Trasdeza: una economía rural antigua. Población y economía en la antigua jurisdicción de Trasdeza, Universidad de Santiago, 1973.

3 A mediados del siglo XVIII, alrededor del 90 por cien de las cargas satisfechas por los campesinos estaba constituido por foros, arriendos y diezmos; cfr. SAAVEDRA, P.: Señoríos y comunidades campesinas. Aportaciones a la historia rural de la España Moderna, A Coruña, Fundación Pedro Barrié de la Maza, 2003, p. 81.

4 Cfr. VILLARES, R.: "La economía del clero regular gallego ante la desamortización”, Cuadernos de Estudios Gallegos, XXXII (1981), pp. 81-139; BURGO, C.: "Un dominio monástico femenino en la edad moderna: el monasterio benedictino de San Payo de Antealtares", Tesis doctoral inédita, Univ. de Santiago, Facultad de Geografía e Historia, 1986; RIONEGRO FARIÑA, I.: La estructura económica del Císter orensano en la fase final del Antiguo Régimen, Ourense, Caixa Ourense, 1998. Los cabildos y mitras episcopales solían arrendar la cobranza de las rentas; vid. EIRAS ROEL, A.: Estudios sobre agricultura y población en la España Moderna, Universidad de Santiago de Compostela, Tórculo Edicións, 1990, y REY CASTELAO, O.: "La renta del voto de Santiago y las instituciones jacobeas", Compostellanum, 30 (1985), pp. 323-386. Por nuestra parte tenemos pendiente de entregar a la imprenta una voluminosa investigación, fruto del trabajo de muchos años, y que lleva por título provisional Monasterios y pazos en la Galicia Moderna. 
al mercado unos 800.000 hls, una cantidad suficiente para alimentar una ciudad de $200.000 \mathrm{hbs}$, cuando la población urbana de Galicia no pasaba de $60.000^{5}$. Si no había a la sazón, ni en general en el siglo XVIII, exportación regular de cereales, hay que preguntarse en dónde colocaban los rentistas tal volumen de excedentes, que las ciudades y villas del Reino estaban lejos de poder consumir en su totalidad.

Las formas concretas de comercialización de esa ingente masa de cereales, que sobraría para abastecer una ciudad como Madrid a finales del XVIII ${ }^{6}$, aparecen apenas declaradas en los libros de cuentas de las paneras monásticas, de prioratos y de casas de la nobleza e hidalguía. Es sabido que los monjes cistercienses que tenían a su cargo alguna administración de la comunidad (la panera, la bodega, un priorato, la caja) solían rendir cuentas el 15 de abril de cada año, fecha que también servía de inicio y final del cómputo para proceder a la realización de los "estados generales" que se efectuaban en el momento previo a la partida del abad al capítulo general, reunión en la que se procedía a la renovación de cargos (cada tres años hasta 1759, cada cuatro después) 7 . Año tras año, por tanto, a mediados de abril, los padres paneros, los bodegueros y los monjes granjeros nos informan de la cuantía y destino de los ingresos de la cosecha del verano-otoño anterior, parte de la cual está todavía "en ser", porque debe cubrir las necesidades de todo tipo que haya hasta la recolección próxima. Las existencias no gastadas se añadirán al cargo de las entradas, por foros, diezmos, etc., correspondientes a la cosecha venidera, con lo cual, aunque los monjes administradores señalan que rinden las cuentas de los frutos del año anterior al 15 de abril, mezclan en realidad ingresos pertenecientes a dos años-cosecha (y puede que a más, pero ese ya es otro problema que varía con la coyuntura, y que también habrá que analizar $)^{8}$.

A las dificultades derivadas de la fecha de comienzo y fin de cada ejercicio, en la que se exponen los "cargos" y "descargos" (mezclando al menos las rentas de dos años-cosecha, reiteramos), se añade el que los diversos libros de cuentas rara vez informan de los procesos concretos de venta: número de operaciones, volumen ne-

5 Cfr. EIRAS ROEL, A.: "Una primera aproximación a la estructura demográfica urbana de Galicia en el censo de 1787", en VILLARES, R. (Coord.): La ciudad y el mundo urbano en la historia de Galicia, Santiago de Compostela, Tórculo edicións, 1988, pp. 155-177, y CARMONA, J.: El atraso industrial de Galicia. Auge y liquidación de las manufacturas textiles, 1750-1900, Barcelona, Ariel, p. 35.

6 Vid. RINGROSE, D.: Madrid y la economía española, 1560-1850, Madrid, Alianza, 1985, p. 136 ss., y CASTRO, C.de: El pan de Madrid. El abasto de las ciudades españolas en el Antiguo Régimen, Madrid, Alianza, 1987, p. 282 y ss.

7 Cfr. MARTíN, E.: Los bernardos españoles (Historia de la Congregación de Castilla de la orden del Císter), Palencia, Gráficas Aguado, 1953; LÓPEZ GARCÍA, J.M: La transición del feudalismo al capitalismo en un señorío monástico castellano: el abadengo de la Santa Espina (1147-1835), Valladolid, Junta de Castilla y León, 1990 y RIONEGRO FARIÑA, I.: La estructura económica del Císter orensano en la fase final del Antiguo Régimen, Ourense, Caixa Ourense, 1998.

8 Esto queda de manifiesto en todos los libros de panera, bodega y de prioratos que hemos consultado, de los cuales sólo se utilizan en este trabajo unos pocos. 
gociado, fecha precisa, lugar y participantes. Es más, resulta claro, una vez adquirida una cierta familiaridad con la documentación, que no siempre se distingue el cereal vendido del cobrado a dinero (con independencia del año a que corresponda), e incluso a veces se dan por vendidas cantidades que figuran en memoriales de deudas cobrables a los precios fijados por los justicias locales ${ }^{9}$. En las contabilidades de casas hidalgas a los mayordomos se les hace cargo, en ocasiones, del valor en reales al que se supone que debieron vender todas o la mayor parte de las rentas, de acuerdo con los precios fijados por las justicias locales, según certificados de fe de valores, tal como ocurre en varias administraciones del conde de Amarante. Esta práctica respondía a las condiciones pactadas previamente entre el señor y el aspirante a la mayordomía.

Estos problemas son, al menos parcialmente, conocidos, pero conviene exponerlos con claridad por lo que afectan al análisis y explicación de los procesos concretos de comercialización de voluminosos excedentes creados y al tiempo consumidos en una proporción muy elevada por pequeños campesinos que, en teoría, aspiraban a la autosuficiencia y no tendrían apenas contacto con el mercado. Pues, avanzando conclusiones cabe afirmar que lo que a la postre sucede, al menos en el siglo XVIII y primer tercio del XIX, es que la adquisición y consumo de las cantidades correspondientes a foros, arriendos y diezmos, tenía lugar con frecuencia en el mundo rural, antes que en mercados urbanos, capaces de absorber sólo una pequeña parte del excedente total. Y si eran los propios campesinos quienes compraban los cereales sacados a la venta por instituciones y casas rentistas, ello tuvo que afectar a la dinámica de la propia economía campesina, cada vez más influida por el mercado ${ }^{10}$, y condicionar al tiempo las propias formas de comercialización, ya que no es lo mismo vender en grandes mercados urbanos, sometidos en algún grado a las reglas impersonales de la oferta y la demanda -aunque en la corona de Castilla estaban muy intervenidos-, que negociar en el mundo rural hoy con unos pocos campesinos y mañana con otros, cuyas necesidades y capacidad de pago y hasta su relación con la institución o casa rentista vendedora podían ser muy variables, y no todos los colonos merecían el igual trato.

9 Así consta en el libro de caja de Sobrado, de la primera mitad del XVIII (Arquivo do Reino de Galicia, Monasterios, Sobrado, libro 443). Lo apunta también, a propósito del cenobio leonés de Villaverde de Sandoval, SEBASTIÁN AMARILLA, J.A.: "Propiedad señorial, captación del producto agrario y estrategias de comercialización: el ejemplo de un monasterio leonés de comienzos del siglo XVI a 1835”, Noticiario de Historia Agraria, 4 (1992), pp. 251-282.

10 Según planteó en su día, en un artículo que se ha convertido en clásico, AYMARD, M.: “Autoconsommation et marchès: Chayanov, Labrousse et Le Roy Ladurie”, Annales, 38 (1983), pp. 1.3921.410; sobre el campesinado cántabro en la etapa final del Antiguo Régimen, DOMÍNGUEZ MARTÍN, R.: El campesinado adaptativo. Campesinos y mercado en el Norte de España, 1750-1880, Santander, Universidad de Cantabria / Asamblea Regional de Cantabria, 1996. 
Estas cuestiones, o sea, los mecanismos informales y opacos de comercialización, son los que con preferencia interesan aquí por lo que condicionaban la economía rentista y por lo que desvelan del funcionamiento concreto de las economías campesinas.

\section{La trayectoria de los "alcances" y su explicación}

Los libros de cuentas, abundantes y con caudalosa información, a primera vista muy exhaustiva, adolecen no obstante de un indudable carácter teórico: reflejan ante todo los ingresos que en cada ejercicio debió cobrar el mayordomo que los tenía a su cargo, así como el destino que les dio. Ahora bien, la cobranza regular de todas las rentas constituía la excepción y no la regla, y el problema subyacente de las deudas crónicas queda a menudo embozado, salvo cuando alcanzaban dimensiones extraordinarias; entonces ya no era posible mantener la ficción de que los ingresos reales coincidían con los teóricos y había que quitar del cargo o recibo las cantidades incobrables.

Esta realidad, imprescindible para interpretar con un mínimo de fiabilidad los datos de las fuentes contables, nos obliga a detenernos, en primer lugar, en las partidas que figuran como alcance o remanente teórico con que se finalizaba o iniciaba cada ejercicio, y después en las que figuran como supuestamente vendidas en mercados y fechas que no suelen especificarse. Hay que atender, preferentemente, a aquellos productos que formaban el acervo fundamental de los ingresos en especie y que se destinaban en buena medida a la venta; el centeno, en primer lugar, y también el mijo y el maíz, y el vino, mientras el trigo, con frecuencia consumido e incluso comprado para tal fin, tiene al respecto menos interés, salvo como prueba a contrario.

Las reservas para gastar desde abril a septiembre sirven tan sólo para justificar una porción de los alcances, y no los volúmenes que se acercan o están incluso por encima de los ingresos anuales. Pero, además, en los prioratos, en donde los gastos de funcionamiento representaban por término medio del 8 al 15 por cien de los ingresos, los remanente no pueden explicarse como reservas almacenadas para futuras urgencias, $\mathrm{y}$, en consecuencia, o bien son cantidades que los monjes granjeros no quisieron o no pudieron vender, o bien atrasos que asentaron en el cargo porque debían -en teoría- cobrarlos, y en el descargo como existencias porque no los gastaron, cosa que mal podían hacer si los colonos no los habían pagado ${ }^{11}$.

Una realidad que se constata en los libros de paneras y prioratos, y cuya interpretación no siempre resulta fácil, es la disminución del porcentaje que representan los alcan-

11 Breves consideraciones al respecto en RIONEGRO FARIÑA, I.: "Contabilidad monástica: fuentes, problemas y método para su interpretación”, Homenaxe á profesora Lola F. Ferro: estudios de historia, arte e xeografia, Servizo de Publicacións da Universidade de Vigo, 2005, pp. 491-512. 
ces con respecto al recibo teórico o ingresos correspondientes a cada ejercicio. Veámoslo en el caso de Oseira, con datos que se refieren a la panera y a todos los prioratos:

\begin{tabular}{|c|c|c|c|}
\hline \multicolumn{4}{|c|}{$\begin{array}{l}\text { Cuadro } 1 \\
\text { Evolución alcances de centeno de Oseira. Media anual en fanegas }\end{array}$} \\
\hline Abril-Abril & 1. Alcance & 2. Recibo teórico & $\% 1 / 2$ \\
\hline $1620-50$ & $2.230,25$ & $6.149,25$ & 36,3 \\
\hline $1653-74$ & $3.102,75$ & 6.442 & 48,2 \\
\hline $1677-1701$ & $2.028,75$ & 6.630 & 30,6 \\
\hline $1704-24$ & 1.724 & $6.646,5$ & 25,9 \\
\hline $1727-50$ & $3.111,4$ & 6.768 & $46,-$ \\
\hline $1753-75$ & $1.073,5$ & $6.794,5$ & 15,8 \\
\hline 1779-99 & 1.350 & 6.930 & 19,5 \\
\hline $1803-19$ & $\begin{array}{c}886,25 \\
(0 ́ 821,25)^{*}\end{array}$ & $6.601,5$ & $\begin{array}{l}13,4 \\
(12,4)^{*}\end{array}$ \\
\hline $1828-32$ & $\begin{array}{c}916,5 \\
(00731,5)^{*}\end{array}$ & $7.207,5$ & $\begin{array}{c}12,7 \\
(10,1)^{*}\end{array}$ \\
\hline
\end{tabular}

Hasta mediados del XVIII los remanentes suponían de un tercio a la mitad de los ingresos teóricos de cada año, mientras después notan una drástica reducción que los sitúa por debajo del 20 e incluso del 15 por cien en el primer tercio del XIX. Ello significa que si una parte de los alcances estaba constituida en realidad por deudas -no cobradas, pero consideradas cobrables-, éstas disminuyen en la etapa final del Antiguo Régimen, lo que va en contra de los resultados de la mayor parte de las investigaciones, que insisten en las resistencias e impagos de rentas en los decenios anteriores a la exclaustración. Otras posibles explicaciones de esa trayectoria evolutiva habría que buscarlas en el abandono de prácticas de almacenamiento, e incluso en cambios en los criterios con los que se llevaba la contabilidad ${ }^{12}$.

Los alcances o remanentes de centeno, representa, en efecto, una proporción muy elevada de las disponibilidades teóricas anuales en el siglo XVII y en la primera mitad del XVIII. En las paneras centrales, en donde el gasto era copioso, este hecho podría tener una parcial justificación en que desde el cierre de cuentas -mediados de abril, recuérdese- hasta la cobranza de las rentas de la próxima cosecha transcurrían cuatro o cinco meses y las constituciones del Císter ordenaban guardar existencias

12 Avanzada la primera mitad del XVII, el monasterio cisterciense de Villaverde de Sandoval desiste de almacenar, a la espera de mejores precios, grandes cantidades de trigo, pues los resultados de tal práctica son, a menudo, negativos. Vid. SEBASTIÁN AMARILLA, J.A.: "Propiedad señorial, captación del producto...", y más extensamente, Agricultura y rentas monásticas en tierra de León. Santa María de Sandoval (1167-1835), Universidad Complutense de Madrid, 1992, vol. II, p. 813 y ss. 
suficientes para el consumo que se estimaba inexcusable. Así se hace constar, por ejemplo, en el libro de estado del monasterio de Oseira.

La progresiva reducción de los alcances es un hecho acreditado por muchos otros libros de paneras y prioratos. En el caso del monasterio de Monfero hay también información para la casa central y para los prioratos, y aunque no alcanza una cronología tan dilatada como en Oseira, los resultados parecen concluyentes y se refieren además a tres tipos de cereales.

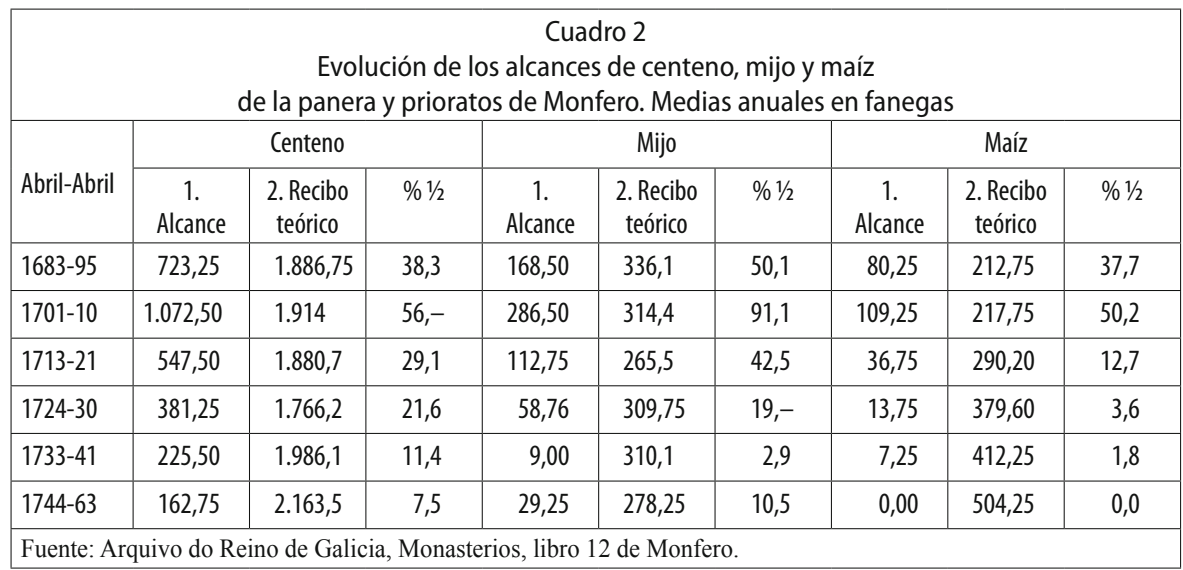

Los remanentes suponen proporciones elevadas hasta principios del XVIII, pero en el segundo cuarto de esta centuria la situación cambia radicalmente: poco es el centeno que parece guardarse de un ejercicio para otro, menos aún el mijo en tanto el maíz acaba siendo despachado todo antes de mediados de abril del año siguiente. Se trata, según quedó advertido, de una evolución generalizada, aunque no siempre tan acentuada como en este cenobio, con muchas rentas proporcionales y con ingresos diversificados, entre los cuales el maíz adquirió una importancia creciente, pero acabó destinándose por completo a la venta (y por lo mismo no había necesidad de guardar cantidades para consumo ordinario, lo que no sucedía en otros cenobios, según se vio) ${ }^{13}$.

El proceso puede aclararse tal vez un poco atendiendo de modo diferenciado a paneras centrales y prioratos, por cuanto en las primeras tenían que guardar siempre mayores reservas hasta las rentas de las próximas cosechas, por las proporciones que alcanzaba el gasto ordinario. Por ello los alcances mantienen a menudo una mayor esta-

13 En la mencionada monografía Monasterios y pazos estudiamos de modo detallado la composición de los ingresos cerealeros de diversas casas centrales y de prioratos y granjas, su trayectoria evolutiva y su destino. Para el caso de Oseira, vid. SAAVEDRA, P.: "Economías cistercienses del Antiguo Régimen. El imperial monasterio de Oseira", en el volumen-homenaje que la Universidade de A Coruña dedica al prof. Baudilio Barreiro, coordinado por M. R. García-Hurtado (en prensa). 
Cuadro 3

Evolución de los alcances de las paneras de Melón y Penamaior. Medias anuales en fanegas

a) Melón

\begin{tabular}{|c|c|c|c|c|c|c|c|c|c|}
\hline \multirow{2}{*}{ Años } & \multicolumn{3}{|c|}{ Centeno } & \multicolumn{3}{c|}{ Mijo } & \multicolumn{3}{c|}{ Maíz } \\
\cline { 2 - 10 } & $\begin{array}{c}1 . \\
\text { Alcance }\end{array}$ & $\begin{array}{c}2 . \text { Recibo } \\
\text { teórico }\end{array}$ & $\% 1 / 2$ & $\begin{array}{c}1 . \\
\text { Alcance }\end{array}$ & $\begin{array}{c}2 . \text { Recibo } \\
\text { teórico }\end{array}$ & $\% 1 / 2$ & $\begin{array}{c}1 . \\
\text { Alcance }\end{array}$ & $\begin{array}{c}\text { 2.Recibo } \\
\text { teórico }\end{array}$ & $\% 1 / 2$ \\
\hline $1675-79$ & 39,30 & 360,20 & 10,9 & 42,70 & 252,00 & 16,9 & - & - & - \\
\hline $1680-89$ & 141,00 & 394,75 & 35,7 & 79,25 & 254,20 & 31,2 & - & - & - \\
\hline $1690-99$ & 56,00 & 372,50 & $15,-$ & 34,00 & 209,00 & 16,3 & 38,50 & 231,75 & 16,6 \\
\hline $1700-09$ & 75,80 & 431,75 & 17,6 & 63,80 & 228,25 & $28,-$ & 58,00 & 274,40 & 21,1 \\
\hline $1710-19$ & 61,00 & 424,25 & 14,4 & 61,25 & 232,00 & 26,4 & 2,00 & 271,00 & 0,74 \\
\hline $1720-29$ & 99,50 & 428,50 & 23,2 & 71,40 & 244,90 & 29,2 & 72,00 & 279,50 & 25,8 \\
\hline $1730-39$ & 84,10 & 411,75 & 20,4 & 56,50 & 245,50 & $23,-$ & 158,00 & 266,25 & 59,3 \\
\hline $1740-49$ & 75,40 & 424,50 & 17,8 & 71,50 & 247,30 & 28,9 & 41,10 & 271,00 & 15,2 \\
\hline $1750-59$ & 83,20 & 415,00 & $20,-$ & 73,70 & 246,20 & 29,9 & 18,80 & 269,70 & $7,-$ \\
\hline $1760-69$ & 59,70 & 444,50 & 13,4 & 64,00 & 251,50 & 25,4 & 0,00 & 269,25 & $0,-$ \\
\hline $1770-79$ & 45,50 & 411,30 & 11,1 & 47,70 & 246,00 & 19,4 & 0,00 & 269,25 & $0,-$ \\
\hline $1780-89$ & 46,90 & 413,20 & 11,4 & 34,40 & 248,00 & 13,9 & 0,00 & 269,25 & $0,-$ \\
\hline $1790-99$ & 43,60 & 416,50 & 10,5 & 37,10 & 252,15 & 14,7 & 5,10 & 269,10 & 1,9 \\
\hline $1800-09$ & 37,20 & 420,10 & 8,9 & 37,25 & 252,75 & 14,7 & 14,40 & 269,00 & 5,4 \\
\hline $1810-11$ & 37,20 & 419,50 & 8,9 & 36,90 & 252,25 & 14,6 & 21,10 & 269,00 & 7,8 \\
\hline $1824-29$ & 80,60 & 326,25 & 24,7 & 63,80 & 173,00 & 36,9 & 72,90 & 245,00 & 29,8 \\
\hline $1830-34$ & 47,90 & 376,50 & 12,7 & 48,60 & 210,75 & 20,2 & 120,70 & 269,00 & 44,9 \\
\hline
\end{tabular}

b) Penamaior

\begin{tabular}{|c|c|c|c|}
\hline \multirow[t]{2}{*}{ Años } & \multicolumn{3}{|c|}{ Centeno } \\
\hline & 1. Alcance & 2. Recibo teórico & $\% 1 / 2$ \\
\hline $1675-79$ & 302,6 & $1.011,2$ & 29,9 \\
\hline $1680-89$ & 454,3 & $1.057,7$ & $43,-$ \\
\hline $1690-99$ & 431,25 & $1.058,75$ & 40,7 \\
\hline $1700-09$ & 397,5 & $1.116,6$ & 35,6 \\
\hline $1710-19$ & 454,3 & $1.118,7$ & 40,6 \\
\hline $1720-29$ & 184,2 & $1.131,8$ & 16,3 \\
\hline $1730-39$ & 117,5 & $1.132,25$ & 10,4 \\
\hline $1740-49$ & 91,25 & $1.139,25$ & $8,-$ \\
\hline $1750-59$ & 80,9 & $1.149,1$ & $7,-$ \\
\hline $1760-69$ & 74,5 & $1.125,75$ & 6,6 \\
\hline $1770-79$ & 141,5 & $1.116,-$ & 12,7 \\
\hline $1780-89$ & 291,25 & $1.112,5$ & 26,2 \\
\hline $1790-99$ & 121,25 & $1.111,5$ & 10,9 \\
\hline 1800-09 & 159,25 & $1.127,25$ & 14,1 \\
\hline $1810-18$ & 80,25 & $1.117,75$ & 7,2 \\
\hline $1824-29$ & 191,25 & $1.113,5$ & 17,2 \\
\hline $1830-34$ & 88,6 & $1.120,4$ & 7,9 \\
\hline
\end{tabular}

Fuente: Elaboración a partir del Arquivo Histórico Provincial de Ourense, Clero, libro 387, y Archivo Histórico Nacional, Clero, libro 6.161. 
bilidad, aunque la tendencia a disminuir no deja de percibirse en varios casos, en particular cuando los datos permiten comparar el XVII con el XVIII y primer tercio del XIX (vid. cuadro 3).

Los padres paneros de Melón anotan unos alcances de mijo y centeno parecidos en el volumen y en la tendencia (con un descenso, ya visto en casos anteriores, en la segunda mitad del XVIII y un ligero incremento después del Trienio) ${ }^{14}$, mientras los de maíz son insignificantes o nulos salvo en los años primeros de su cobranza, en las décadas de 1720 y 1730 y en los momentos previos a la exclaustración. En particular en los diversos balances de 1729-38 se registraron año tras año remanentes de maíz, sin que los monjes aclaren si se trata de stocks o de deudas ${ }^{15}$. Dado el nivel a que cayeron los precios en ese ciclo, podían componerse de cereal almacenado de un ejercicio para otro, pues cuando a partir de la cosecha de 1738 las cotizaciones tendieron al alza, sólo de modo esporádico aparecen alcances, hasta que en 1787, a raíz de la entrada del maíz en el consumo ordinario de personas o animales, los padres paneros han de reservar algunas cantidades para los gastos previstos desde mediados de abril a octubre, tiempo de la recolección ${ }^{16}$. Después del Trienio las deudas parecen afectar más al maíz que al resto de los cereales, al menos en el quinquenio que precede a la desamortización.

En el caso de la pequeña panera de Penamaior se advierte una reducción muy acusada de los remanentes teóricos desde comienzos del XVIII, hasta quedar limitados poco más que a las cantidades que necesitaba la "familia monástica", los animales y los operarios eventuales para alimentarse de abril a septiembre. Las propias dimensiones de la comunidad, una breve presidencia, que permitían destinar a la venta alrededor del 70 por cien del centeno de la panera -sólo el 45 por cien en Melón-, explican que pudiese funcionar con tan cortos alcances, aunque no dan cuenta de por qué hasta entrado el XVIII alcanzaban cifras tan altas ${ }^{17}$.

14 En especial desde mediados de la década de 1760 los alcances de centeno y mijo están constituidos por cantidades estables, que se repiten varios años, para ser sustituidas por otras más bajas, lo que denota que se trata de fondos para afrontar las necesidades previas a la cosecha y pago de rentas del próximo ejercicio. El mismo hecho se advierte en la panera de Franqueira.

15 Un análisis año por año, que aquí no efectuamos, permitiría matizar los datos resultantes de los cálculos de medias por decenio.

16 Para los precios, EIRAS ROEL, A. y USERO GONZÁLEZ, R.: "Los precios de los granos en Santiago de Compostela y Mondoñedo. Siglo XVIII", en EIRAS ROEL, A. et alii.: Las Fuentes y los Métodos. Quince trabajos de historia cuantitativo-serial de Galicia, Universidade de Santiago de Compostela, 1977, pp. 243-288.

17 Dentro de las comunidades cistercienses de Galicia, Acibeiro, A Franqueira y Penamaior, tenían la condición de "presidencia"; sus ingresos globales eran cortos y reducido el número de monjes. Cfr. FERNÁNDEZ CORTIZO, C.: "La reforma de las órdenes de San Benito y del Císter en Galicia", en EIRAS ROEL, A. (Coord.): El Reino de Galicia en la época del emperador Carlos V, Santiago de Compostela, Xunta de Galicia, 2000, pp. 847 y ss., y, con carácter general, Fr. YÁÑEZ NEIRA, D. et alii,: Monasticón cisterciense gallego, León, Caixa Vigo e Ourense, 2000, 2 vols., con una breve historia de cada monasterio. 
En las paneras de Montederramo, y sobre todo de Oseira, por las urgencias de un elevado consumo o gasto ordinario la estabilidad de los alcances parece mayor, si bien los datos con que contamos son demasiado tardíos:

Cuadro 4

Evolución de los alcances de centeno de las paneras de Montederramo y Oseira, en fanegas

\begin{tabular}{|l|c|c|c|c|c|c|}
\hline \multirow{2}{*}{ Años } & \multicolumn{5}{|c|}{ Montederramo } & \multicolumn{3}{c|}{ Oseira } \\
\cline { 2 - 7 } & $\begin{array}{c}1 . \\
\text { Alcance }\end{array}$ & $\begin{array}{c}2 . \text { Recibo } \\
\text { teórico }\end{array}$ & $\% 1 / 2$ & $\begin{array}{c}1 . \\
\text { Alcance }\end{array}$ & $\begin{array}{c}\text { 2. Recibo } \\
\text { teórico }\end{array}$ & $\% 1 / 2$ \\
\hline $1717-19$ & 575,50 & $1.732,00$ & 33,2 & & & \\
\hline $1720-29$ & 367,80 & $1.761,25$ & 20,9 & 551,80 & $1.265,90$ & 43,6 \\
\hline $1730-39$ & 300,00 & $1.768,50$ & $17,-$ & 519,00 & $1.321,00$ & 39,3 \\
\hline $1740-49$ & 294,00 & $1.744,75$ & 16,9 & 699,20 & $1.158,50$ & 60,4 \\
\hline $1750-59$ & 262,50 & $1.775,50$ & 14,8 & 694,10 & $1.151,00$ & 60,3 \\
\hline $1760-69$ & 248,75 & $1.718,50$ & 14,5 & 758,00 & $1.187,25$ & 63,8 \\
\hline $1770-79$ & 437,25 & $1.753,75$ & 24,9 & 661,50 & $1.227,50$ & 53,9 \\
\hline $1780-89$ & 356,50 & $1.826,00$ & 19,5 & 623,40 & $1.111,25$ & 56,1 \\
\hline $1790-99$ & 406,00 & $1.842,00$ & $22,-$ & 624,50 & $1.070,25$ & 58,4 \\
\hline $1800-09$ & 367,75 & $1.807,25$ & 20,3 & 612,30 & $1.083,00$ & 56,5 \\
\hline $1810-19$ & 940,50 & $1.706,25$ & 55,1 & 513,40 & 961,60 & 53,4 \\
\hline $1824-29$ & 623,00 & $1.685,40$ & $37,-$ & 537,00 & 936,50 & 57,3 \\
\hline $1830-34$ & 537,00 & $1.706,20$ & 31,5 & 463,00 & 905,75 & 51,1 \\
\hline Fuente: Elaboración a partir del Arquivo Histórico Provincial de Ourense, Clero, libros 458 y 620. \\
\hline
\end{tabular}

En la comunidad de Montederramo los cambios no son, en apariencia, muy relevantes, porque el volumen de los remanentes se mantiene siempre bastante elevado. Del análisis de los datos anuales se desprende que desde el ecuador del siglo XVIII los padres paneros tendieron a cerrar los ejercicios con un stock fijo de 200 fanegas, sin duda para hacer frente al gasto ordinario y de limosnas previsto hasta la próxima cosecha, práctica interrumpida algunos años de modo brusco, o porque no quisieron vender los excedentes a precios que no estimaban suficientes, o porque debieron afrontar atrasos posteriormente recuperados. En todo caso, hubo años en que vendieron grandes cantidades a precios más bien bajos, lo que apunta a problemas puntuales de comercialización en una comarca rural y montañosa, y la comunidad monástica no acumuló remanente dos ejercicios seguidos: si quedaban de un año se deshacían de ellos al siguiente ${ }^{18}$. Tan sólo a partir de la guerra de la Independencia se

18 De la cosecha de 1753 queda un remanente de 826,75 fanegas, que se comercializan en el ejercicio cerrado en abril de 1755 a 16,9 reales (junto con otros de la cosecha de 1754, hasta alcanzar las 1.707 fanegas vendidas); cuando antes valieran a 22,5; de la cosecha de 1765 quedaron 687 fanegas, lo que permitió vender en el siguiente ejercicio 1.455 a 25 , frente a los 17,5 del año anterior, pero muy por debajo de los 46,25 del ejercicio de IV/1768 a IV/1769; de la cosecha de 1786 se guardan 1.035,25 fanegas, 
repiten en el cargo y descargo por cuantías elevadas (de las cosechas de 1810, 1812, $1813,11814,1815,1816$ y 1818, 1824-26), lo que deriva de atrasos de los colonos, en gran parte recuperados a juzgar por el volumen de ventas de determinados años ${ }^{19}$. El repunte de la cuantía de los alcances se advierte también en la panera de Xunqueira desde el Trienio y ha de explicarse también a partir del incremento de los atrasos de los campesinos, que cuando son cobrados, permiten a los padres paneros aumentar notablemente el volumen de las ventas ${ }^{20}$.

La panera de Oseira suministra una prueba a contrario de que la evolución de los alcances tiene mucho que ver con los procesos de comercialización. Al revés de lo que sucedía en otros casos antes analizados -Melón, Penamaior-, los padres paneros de Oseira observaron un comportamiento mucho más regular desde la década de 1720 hasta la exclaustración. A excepción del último quinquenio, los remanentes superan siempre las 500 fanegas, rondan las 700 en 1740-59 y sobrepasan las 750 en 1760-69, representando por término medio un tercio largo de las disponibilidades teóricas anuales. La explicación de esta trayectoria, caracterizada por la ausencia de cambios y que por lo mismo contrasta con las comentadas anteriormente, radica en que la panera de Oseira no vendía centeno (salvo cortas cantidades en vísperas de la exclaustración), y los elevados stocks han de considerarse ante todo como reservas destinadas a hacer frente a un elevado gasto de limosnas y alimentación de criados, asalariados ocasionales y animales, sostenido a lo largo del año ( y el de limosnas incrementado incluso en los meses de soldadura $)^{21}$. Parece, por lo mismo, que los datos de la panera del gran cenobio de Oseira confirman que cuando hay grandes oscilaciones en el volumen y

vendidas luego a 26,6 reales, cuando en el anterior año valieran a 36,2 y en el siguiente a 42,9. Otro caso parecido los años cosecha de 1794 y 1795, y en los de 1806 y 1807. También los hay del tenor contrario, en los que se ve que la acumulación de stocks y luego la concentración de ventas dio buenos resultados financieros: en las cosechas de 1778 y 1779 ; en las de 1780 y 1781; en las de 1798 y 1799; en las de 1802 y $1803 . .$. Vid. también, RIONEGRO FARIÑA, I.: La estructura económica del Císter..., p. 79 y ss., con datos por quinquenios a partir de 1750 .

19 Desde la guerra de la Independencia se registra una fuerte oscilación de las ventas. Significativamente el ejercicio en que se comercializa la cantidad más alta -2.626 fanegas- es el de IV/1813 a IV/1814, seguido del de IV/1834 a IV/1835 -2.206 fanegas-, cuando los monjes lograron cobrar o vender buena parte de los atrasos acumulados (de unas disponibilidades de 2.925,25 fanegas, incluidas 1.239,5 de alcance, gastaron y vendieron 2.617, quedando reducido el alcance a 308,25 fanegas).

20 En Xunqueira el alcance o remanente ordinario se situaba por norma en 100 fanegas, aunque algunos años de la década de 1780 multiplicó por 4 esa cantidad; tanto en este monasterio como en el de Montederramo, desde 1811 o 1824 el cereal comercializado oscila fuertemente de un año a otro, por los efectos de las deudas y su posterior cobranza. Arquivo Histórico Provincial de Ourense, clero, libro 795. En este caso las cuentas son más tardías y no empiezan hasta la década de 1770. Datos quinquenales de ingresos y gastos en RIONEGRO, I.: La estructura económica del Císter..., p. 160 y ss.

21 RIONEGRO, I.: La estructura económica del Císter..., p. 316 y ss. La trayectoria de los ingresos globales del cenobio y la comparación entre prioratos y casa central, en SAAVEDRA, P.: "Economías cistercienses...". 
porcentajes de los alcances es debido a las fluctuaciones de la deuda y a posibles cambios en los mecanismos de comercialización; cuando los alcances están constituidos ante todo por reservas para gasto ordinario las oscilaciones son mucho menores. Si se comparan los datos de la panera de Oseira con las generales que incluyen también los prioratos (cuadro 1, supra), se ve que éstos bajan del 46 por cien en 1727-50 a menos del 20 y aun del 15 en los siguientes periodos, mientras en la casa central el alcance representó siempre más del 50 por cien por relación al recibo de cada año.

La panera que, a largo plazo, registra los cambios más espectaculares en lo tocante al volumen y proporción de los alcances de centeno es la de Sobrado, que tenía un gasto ordinario comparable al de Oseira, pero a diferencia de este comercializaba de dos tercios a tres cuartas partes de las entradas, muy superiores a las del cenobio orensano.

\section{Cuadro 5}

Trayectoria de los alcances de centeno de la panera de Sobrado. Medias anuales en fanegas

\begin{tabular}{|l|c|c|c|}
\hline Años Abril-Abril & 1. Alcance & 2. Recibo teórico & $\%$ 1/2 \\
\hline $1623-36$ & $1.633,50$ & $3.589,80$ & 45,5 \\
\hline $1650-74$ & $6.899,25$ & $3.580,75$ & 192,2 \\
\hline $1674-1701$ & $6.252,75$ & $3.662,30$ & 170,7 \\
\hline $1702-24$ & $2.943,25$ & $3.669,00$ & 80,2 \\
\hline $1724-50$ & $2.718,75$ & $3.550,25$ & 76,6 \\
\hline $1750-75$ & $2.489,00$ & $3.638,90$ & 68,4 \\
\hline $1775-99$ & $1.617,75$ & $3.469,50$ & 46,6 \\
\hline $1799-1819$ & $1.467,50$ & $3.520,60$ & 41,7 \\
\hline $1828-32$ & 830,50 & $3.425,60$ & 24,2 \\
& $(250)^{*}$ & $(7,30)^{*}$ \\
\hline * Según se compute el comienzo o el final del ejercicio de 1828 (remanente 1824). \\
Fuente: Arquivo do Reino de Galicia, Monasterios, Sobrado, libros 19,21 y 446. \\
\hline
\end{tabular}

Los ingresos oscilaron poco a lo largo de esas dos centurias, pero no sucede igual con los alcances o remanentes teóricos, que en la segunda mitad del XVII casi duplican el recibo, y después van reduciéndose hasta alcanzar sus niveles más bajos en vísperas de la exclaustración. Extraña evolución, si a la postre un porcentaje grande de los alcances está constituido por cantidades que no se cobraron en el ejercicio correspondiente, como pronto veremos. Pero antes conviene reparar en los datos correspondientes a tres prioratos, dos de Sobrado -las Cascas y Solme- y otros de Montederramo -Castro de Rei-, en los que se advierte una evolución caracterizada por la reducción paulatina de los alcances, que en las administraciones periféricas no pueden explicarse por almacenamientos para el consumo, que era muy bajo. 


\section{Cuadro 6}

Evolución de los alcances de centeno en los prioratos de Castro de Rei y Solme.

Medias anuales en fanegas

\begin{tabular}{|c|c|c|c|c|c|c|}
\hline \multirow[b]{2}{*}{ Años } & \multicolumn{3}{|c|}{ Castro de Rei } & \multicolumn{3}{|c|}{ Solme } \\
\hline & $\begin{array}{c}1 . \\
\text { Alcance }\end{array}$ & $\begin{array}{l}\text { 2. Recibo } \\
\text { teórico }\end{array}$ & $\% \quad 1 / 2$ & $\begin{array}{c}1 . \\
\text { Alcance }\end{array}$ & $\begin{array}{l}\text { 2. Recibo } \\
\text { teórico }\end{array}$ & $\% \quad 1 / 2$ \\
\hline 1640-49 & 500,75 & 731,00 & 68,5 & 103,25 & 349,75 & 29,5 \\
\hline $1650-59$ & 226,25 & 751,60 & 30,1 & 165,00 & 372,50 & 44,3 \\
\hline $1660-69$ & 123,25 & 788,40 & 15,6 & - & - & - \\
\hline $1670-79$ & 108,75 & 800,50 & 13,6 & - & - & - \\
\hline 1680-89 & 508,00 & 819,80 & 62,0 & 49,25 & 221,70 & 22,2 \\
\hline 1690-99 & 105,00 & 840,70 & 12,5 & 22,75 & 256,40 & 8,9 \\
\hline $1700-09$ & 406,00 & 918,60 & 44,2 & 33,00 & 261,10 & 12,5 \\
\hline 1710-19 & 353,25 & 850,25 & 41,5 & 57,00 & 245,50 & 23,2 \\
\hline $1720-29$ & 36,00 & 819,75 & 4,4 & 78,25 & 210,00 & 37,3 \\
\hline $1730-39$ & 17,90 & 768,00 & 2,3 & 29,25 & 203,75 & 14,4 \\
\hline 1740-49 & 21,25 & 813,50 & 2,6 & 24,00 & 269,60 & 8,9 \\
\hline $1750-59$ & 27,50 & 823,60 & 3,3 & 23,25 & 269,80 & 8,6 \\
\hline 1760-69 & 19,50 & 761,90 & 2,6 & 23,00 & 244,20 & 9,4 \\
\hline 1770-79 & 159,50 & 795,50 & 20,1 & 12,00 & 294,10 & 4,1 \\
\hline 1780-89 & 17,70 & 834,50 & 2,1 & 14,50 & 326,25 & 4,4 \\
\hline 1790-99 & 100,50 & 798,00 & 12,6 & 10,00 & 262,25 & 3,8 \\
\hline $1800-09$ & 72,50 & 787,60 & 9,2 & 10,00 & 257,10 & 3,9 \\
\hline 1810-19 & 168,00 & 725,80 & 23,1 & 10,00 & 243,25 & 4,1 \\
\hline 1824-29 & 119,75 & 820,00 & 14,6 & 2,50 & 303,60 & 0,8 \\
\hline $1830-34$ & 98,25 & 851,80 & 11,5 & 0,00 & 271,60 & 0,0 \\
\hline
\end{tabular}

De cantidades muy elevadas, en valores absolutos y relativos, a mediados del XVII, en la década de 1680 y en los primeros veinte o treinta años del XVIII, se pasa a otras mucho más escasas que llegan a ser insignificantes en la granja de Solme en tanto en Castro de Rei hay un repunte en la etapa final del Antiguo Régimen, motivado sin duda por la acumulación de deudas ${ }^{22}$. Dado que, según quedó advertido, los voluminosos alcances nada tenían que ver con el consumo, muy reducido en los prioratos y granjas, su descenso parece apuntar a la aparición de mecanismos de comer-

22 Las rentas forales de Castro de Rei tenían carácter fijo, y las de Solme eran proporcionales, y ya quedó apuntado que las deudas suelen ser más cuantiosas, en épocas de crisis, en el primer caso. Las cuentas del priorato de Castro de Rei de Lemos (en las proximidades de Sarria) las analicé hace años en "Coyuntura agraria e ingresos señoriales en la Galicia interior y en las mariñas de Betanzos", en Obradoiro de Historia Moderna. Homenaje al Prof. Antonio Eiras Roel en el XXV Aniversario de su Cátedra, Universidade de Santiago de Compostela, 1990, p. 297 y ss. (trabajo reproducido en la colectánea Das casas de morada ó monte comunal, Santiago de Compostela, Xunta de Galicia, 1996). 
Cuadro 7

Evolución de los alcances de centeno y maíz en el priorato de las Cascas.

Medias anuales en fanegas

\begin{tabular}{|c|c|c|c|c|c|c|}
\hline \multirow[t]{2}{*}{ Años } & & Centeno & & & Maíz & \\
\hline & 1. Alcance & $\begin{array}{l}\text { 2. Recibo } \\
\text { teórico }\end{array}$ & 3. $\% 1 / 2$ & 1. Alcance & $\begin{array}{l}\text { 2. Recibo } \\
\text { teórico }\end{array}$ & 3. $\% 1 / 2$ \\
\hline $1626-29$ & 266,30 & 336,75 & 79,1 & - & - & - \\
\hline $1630-39$ & 163,00 & 350,50 & 46,5 & - & - & - \\
\hline $1640-49$ & 258,60 & 387,50 & 66,7 & - & - & - \\
\hline $1650-59$ & 301,50 & 422,75 & 71,3 & - & - & - \\
\hline $1660-69$ & 118,90 & 413,50 & 28,8 & - & - & - \\
\hline $1670-79$ & 201,50 & 401,00 & 50,2 & 7,70 & 22,75 & 33,8 \\
\hline $1680-89$ & 348,75 & 429,75 & 81,2 & 13,70 & 38,50 & 35,6 \\
\hline $1690-99$ & 225,75 & 464,75 & 48,6 & 13,70 & 40,25 & $34,-$ \\
\hline $1700-09$ & 392,00 & 447,75 & 87,5 & 19,80 & 39,50 & 50,1 \\
\hline $1710-19$ & 180,30 & 457,00 & 39,5 & 8,50 & 50,00 & $17,-$ \\
\hline $1720-29$ & 175,00 & 476,75 & 36,7 & 8,30 & 74,00 & 11,2 \\
\hline $1730-39$ & 227,75 & 500,00 & 45,6 & 9,00 & 98,75 & 9,1 \\
\hline 1740-49 & 302,90 & 487,25 & 62,2 & 7,00 & 87,50 & $8,-$ \\
\hline $1750-59$ & 131,00 & 502,25 & 26,1 & 7,80 & 80,75 & 9,7 \\
\hline $1760-69$ & 74,75 & 483,75 & 15,5 & 11,80 & 88,50 & 13,3 \\
\hline $1770-79$ & 40,50 & 491,25 & 8,2 & 5,40 & 101,25 & 5,3 \\
\hline 1780-89 & 28,20 & 547,00 & 5,2 & 5,75 & 132,75 & 4,3 \\
\hline $1790-99$ & 19,75 & 475,50 & 4,2 & 6,70 & 104,50 & 6,4 \\
\hline 1800-09 & 16,20 & 411,50 & 3,9 & 4,70 & 90,75 & 5,2 \\
\hline 1810-19 & 5,80 & 478,00 & 1,2 & 2,40 & 105,10 & 2,3 \\
\hline $1824-29$ & 0,00 & 467,50 & 0,0 & 0,00 & 89,25 & 0,0 \\
\hline $1830-34$ & 0,00 & 491,00 & 0,0 & 0,00 & 131,00 & 0,0 \\
\hline
\end{tabular}

cialización del cereal caracterizados por una mayor agilidad, pues las ventas tienen lugar año a año, sin almacenamientos voluntarios o forzosos.

Los libros de cuentas del priorato de las Cascas permiten ratificar tanto la caída de los alcances conforme avanza el siglo XVIII como el significativo contraste que en este aspecto había entre el centeno y el maíz.

La serie del centeno abarca más de dos siglos y a lo largo de ellos dibuja básicamente dos fases: una hasta el ecuador del XVIII, con alcances muy elevados en valores absolutos y porcentuales; otra en la etapa final del Antiguo Régimen, con cantidades insignificantes, o incluso sin remanentes en los últimos años de vida monástica, dado que después del Trienio, siguiendo una práctica generalizada, la comunidad monástica trata de abaratar la gestión, prescindiendo de criados y bestias de tiro y carga. 
El contraste entre ambos períodos resulta patente en un priorato de voluminosos y diversificados ingresos. En cuanto al maíz, los stocks son siempre muy escasos en cifras absolutas, e incluso van descendiendo conforme aumentan los ingresos de este producto, procedente en su casi totalidad de foros estipulados al cuarto y al quinto. Los datos de otros prioratos de Sobrado coinciden en sustancia con lo de las Cascas: así, en el de Almerezo, con unos ingresos anuales de maíz que oscilaron de 150 a 350 fanegas entre 1677 y 1834, sólo en un ejercicio los alcances estuvieron por encima de las diez fanegas (en IV/1783/IV/1784), y en seis más llegan a siete ${ }^{23}$.

La documentación contable suele distinguir con precisión, en cada ejercicio, el alcance del anterior y el recibo del presente -cuya suma constituye las disponibilidades teóricas del año-, pero, según quedó advertido, es menos explícita a la hora de aclarar como se justifican los alcances, remanentes o cantidades a las que no se dio salida. Sólo en los libros de estado de Oseira y Sobrado aparecen apuntamientos no sistemáticos, que indican que un porcentaje elevado de los alcances está constituido en realidad por deudas consideradas cobrables, correspondiendo el resto a cantidades almacenadas para el consumo o para vender en ocasión propicia, según puede comprobarse en el cuadro 8, de la página siguiente.

Los datos de Oseira son más abundantes y se refieren a todas las administraciones del cenobio. Acreditan que, por lo común, la mayor parte de las cantidades incluidas en la partida de alcances son deudas que el padre panero y los monjes granjeros esperan cobrar en próximos ejercicios; lógicamente, esto se hace más acusado en los años en que aumentan los volúmenes de remanentes teóricos y salvo en momentos concretos en que se producen algunos almacenamientos (IV/1647, IV/1668, IV/1680, IV/1730...). En todo caso, se advierte que, a excepción de fases, puntuales, las deudas no son escandalosas, y tienden a reducirse según avanza el siglo XVIII, algo ya comentado al tratar de la evolución general de los alcances. Hay que reparar, además -esto vale también para Sobrado- que la incidencia de la deuda resultaba en la práctica muy inferior a lo que parece desprenderse de los datos del cuadro (proporción de la deuda con respecto a recibo teórico del año), por cuanto al repetirse de un ejercicio para otro las cantidades atrasadas da la impresión de que todos los años han dejado de cobrarse porcentajes más o menos significativos de los ingresos correspondientes a ese año, cuando se trata de atrasos que se anotan un balance tras otro hasta que se cobran o se descargan por incobrables. De hecho, si comparamos, en el largo plazo, el recibo teórico con el gasto o salidas totales, desde ventas a limosnas y mermas, las diferencias son escasas: para los 212 años, cosecha para los que hay cuentas entre 1617 y 1831, el recibo teórico de Oseira ascendió a un promedio de 6.517,5 fanegas

23 Arquivo do Reino de Galicia, Monasterios, libro 120. 
Cuadro 8

Composición de los alcances de centeno de Oseira (prioratos y panera central) y Sobrado (sólo panera). En fanegas

\begin{tabular}{|c|c|c|c|c|c|c|c|c|}
\hline \multirow{2}{*}{\begin{tabular}{|l|} 
Fecha en \\
que queda el \\
remanente
\end{tabular}} & \multicolumn{4}{|c|}{ Oseira } & \multicolumn{4}{|c|}{ Sobrado } \\
\hline & Stocks & Deudas & $\%$ deudas & $\begin{array}{c}\% \text { deudas / } \\
\text { recibo teórico }\end{array}$ & Stocks & Deudas & $\%$ deudas & $\begin{array}{l}\text { \% deudas } \\
\text { recibo teórico }\end{array}$ \\
\hline IV/1632 & * & * & * & * & 550 & 3.054 & 84,7 & 85,8 \\
\hline IV/1644 & 350 & $2.237(1)$ & 86,5 & 36,4 & 759,5 & 3.133 & 80,5 & 87,1 \\
\hline IV/1647 & 3.762 & 1.302 & 21,5 & 20,4 & 1.100 & $4.369,5$ & 79,9 & 118,6 \\
\hline IV/1650 & 906 & $1.322,5$ & 59,3 & 20,7 & * & * & * & \\
\hline IV/1653 & 408 & 2.189 & 84,3 & 34,3 & 300 & $5.007,5$ & 94,3 & 143,6 \\
\hline IV/1656 & 380 & 2.190 & 85,2 & $34,-$ & 400 & $5.681,75$ & 93,4 & 160,4 \\
\hline IV/1659 & 439,5 & 2.464 & 84,7 & 38,6 & 500 & $6.776,25$ & 93,1 & 192,5 \\
\hline IV/1662 & 1.305 & $1.746(2)$ & 57,2 & 27,4 & 100 & $8.069,5$ & 98,8 & 221,4 \\
\hline IV/1665 & 538 & 2.347 & 81,4 & 37,5 & 500 & $8.306,75$ & 94,3 & 232,9 \\
\hline \begin{tabular}{|l|} 
IV/1668 \\
\end{tabular} & 2.184 & 3.890 & $64,-$ & 60,8 & * & $*$ & * & \\
\hline IV/1671 & 2.131 & 1.085 & 33,7 & 16,5 & 616 & 6.427 & 91,3 & 173,2 \\
\hline IV/1674 & 211 & 1.150 & 84,5 & 17,1 & 360 & $6.732,75$ & 94,9 & 186,9 \\
\hline IV/1680 & 2.812 & 914 & 24,5 & 13,9 & 1.500 & $5.128,75$ & 77,4 & 145,7 \\
\hline IV/1683 & 800 & $2.575,8$ & 76,3 & 40,2 & * & * & * & \\
\hline IV/1686 & 299 & 1.748 & 85,4 & 25,7 & * & * & * & \\
\hline IV/1692 & 377 & $887,6(1)$ & 70,2 & 13,3 & * & * & $*$ & \\
\hline IV/1695 & 299 & $711(1)$ & 70,4 & 10,9 & * & * & * & \\
\hline \begin{tabular}{|l|} 
IV/1698 \\
\end{tabular} & 300 & $1.527(1)$ & 85,6 & 23,1 & 1.000 & 5.172 & 83,8 & 138,9 \\
\hline IV/1701 & 1.350 & 367,2 & 21,4 & 05,7 & * & * & * & \\
\hline \begin{tabular}{|l|l|l|} 
IV/1707 \\
\end{tabular} & 382 & $925,6(1)$ & 70,8 & 13,5 & * & * & * & \\
\hline IV/1713 & 350 & $2.289,6$ & 87,8 & 35,9 & * & * & * & \\
\hline IV/1727 & * & * & $*$ & & 645 & $1.797,5$ & 73,6 & 50,6 \\
\hline IV/1730 & 2.140 & $1.218,8$ & 36,3 & $18,-$ & 1.027 & $2.049,25$ & 66,6 & 57,1 \\
\hline IV/1733 & 498 & $1.663,8$ & 77,0 & 25,5 & * & * & * & \\
\hline IV/1738 & 1.906 & $1.907,8$ & $50,-$ & 28,5 & * & * & * & \\
\hline IV/1741 & 612,4 & $2.744,6$ & 81,8 & 42,6 & * & * & * & \\
\hline IV/1744 & 1.290 & $2.429,4$ & 65,3 & $35,-$ & * & * & * & \\
\hline \begin{tabular}{|l|} 
IV/1747 \\
\end{tabular} & 427 & $2.589,2$ & 85,8 & 35,6 & 300 & $1.993,75$ & 86,9 & 56,9 \\
\hline IV/1750 & 410,8 & 503,8 & 55,1 & 07,2 & 625 & 1.624 & 72,2 & 45,5 \\
\hline IV/1753 & 671,5 & 223,7 & 25,5 & 03,2 & * & * & * & \\
\hline \begin{tabular}{|l|} 
IV/1756 \\
\end{tabular} & 518 & 476 & 53,2 & 06,4 & * & * & * & \\
\hline IV/1759 & 510 & 404,8 & 44,3 & 05,8 & * & * & * & \\
\hline IV/1763 & 496 & 516,6 & 51,0 & 07,5 & 390,5 & 2.306 & 85,5 & 65,3 \\
\hline \begin{tabular}{|l|l} 
IV/1767 \\
\end{tabular} & 520 & 638,4 & 55,1 & 09,2 & 690,5 & 1.777 & 72 & 51,2 \\
\hline IV/1771 & 526 & $1.099,4$ & 67,7 & $18,-$ & * & * & * & \\
\hline IV/1775 & 500 & 1.078 & 68,3 & 16,5 & * & * & * & \\
\hline IV/1779 & 520 & 1.134 & 69,4 & 16,8 & * & * & * & \\
\hline IV/1783 & 650 & $1.335,2$ & 67,3 & 19,1 & $*$ & * & $*$ & \\
\hline IV/1787 & 571,4 & 591,4 & 50,9 & 08,5 & * & * & * & \\
\hline IV/1791 & 440 & 378,8 & 46,3 & 05,3 & * & * & * & \\
\hline
\end{tabular}

* Las fuentes no distinguen la composición del alcance.

(1) Parece desprenderse del contexto.

(2) 1.209 cobrables.

Fuente: Biblioteca del Monasterio de Poio, libro de estado de Oseira, y Arquivo do Reino de Galicia, Monasterios, libros 19 y 21 . 
de centeno, y el gasto -en la terminología monástica- a 6.509,2 una diferencia de 8,3 fanegas al año (el 0,127\% de los ingresos teóricos). Claro que esta comparación enmascara, a diferencia de los porcentajes del cuadro, la incidencia de la deuda, por cuanto en las partidas del gasto se incluyen perdones y cantidades dadas por fallidas; aun así esos capítulos en la larga duración suponen poco, si se repara en el destino de los ingresos de cereales (los perdones, cantidades fallidas se incluyen entonces en el epígrafe "otros"). En el primer tercio del XIX, por ejemplo, considerada época propicia a deudas e impagos, Oseira perdonó de promedio unas 27,5 fanegas de centeno al año de atrasos, un 0,4 por cien de los ingresos teóricos. Esta situación no puede generalizarse a todas las instituciones rentistas, pues había diferencias de unas a otras, e incluso entre administraciones de una misma institución o casa, pero en general no parece que, al menos la economía monástica, se viese muy quebrantada por las deudas fallidas (en Monfero el recibo y el gasto también se equiparan) ${ }^{24}$.

Los datos de Sobrado se refieren sólo a la panera central y aunque tienen poca continuidad sirven para poner de manifiesto que los elevadísimos alcances del XVII no son cantidades almacenadas sino deudas, en este caso muy superiores a las registradas en Oseira. Pero hay que recordar que se trata en buena medida de las mismas cantidades que repiten de un ejercicio para los siguientes, pues de no ser así en el segundo tercio del XVII el padre panero no hubiera visto entrar en las tullas centeno alguno. En cualquier caso, la situación del XVII mejora para el cenobio en la centuria siguiente, una tendencia generalizada, aunque en algunas administraciones interrumpida a principios del XIX.

De todo lo expuesto se desprende, por tanto, que los monasterios acumularon más deudas que stocks para comercializar en ocasiones provechosas. La granería de Sobrado constituye un buen ejemplo, pues los elevadísimos alcances del XVII se corresponden por lo general con impagos, o por malas cosechas o porque los temporales

24 SAAVEDRA, P.: “Economías monásticas cistercienses...”. La resistencia al pago de rentas en la etapa final del Antiguo Régimen es en Galicia limitada territorialmente y suele contar con antecedentes. Cfr. BURGO LÓPEZ, C.: "La conflictividad en torno al pago de la renta foral en Galicia a fines del Antiguo Régimen", Espacio, Tiempo y Forma (Historia Moderna), 4 (1988); REY CASTELAO, O.: "La crisis de la economía de las instituciones eclesiásticas de Galicia”, en SAAVEDRA, P. y VILLARES, R.: Señores y campesinos en la Península Ibérica, siglos XVIII-XX, Barcelona, Crítica / Consello da Cultura Galega, 1991, vol. I, «Os señores da terra», p. 261 y ss., y VELASCO SOUTO, C.: Agitacións campesinas na Galiza do século XIX: resisténcias antisenhoriais no tránsito do Antigo Régime á sociedade liberal (1808-1820), Santiago de Compostela, Laiovento, 1995. Con independencia de problemas financieros derivados de causas diversas (donativos y contribuciones reales, aumento de gastos en pleitos, caída brutal de los precios desde 1817), los monasterios gallegos llegan a la desamortización en una situación mucho menos mala que los del resto de la península. Para el caso de los cistercienses de Ourense, vid. la ya citada monografía de RIONEGRO FARIÑA, I.: La estructura económica del Císter... 
impidieron a los colonos majar y entregar el centeno "limpio de polvo y paja"25. La anotación de abril de 1674, aclaratoria de la situación de la panera valdría, sin duda, para muchos otros ejercicios: "queda de alcance final de centeno catorce mil setecientos setenta y dos celemines, que hacen fanegas siete mil trescientas ochenta y seis fanegas, que se han de cobrar a las valías por no haber[se] podido cobrar en propia especie; queda lo necesario en la panera para el gasto ordinario hasta la cosecha". Pero estas aclaraciones no constituían la norma, y en muchos casos lo habitual era anotar las deudas como cantidades que se esperaba recuperar y vender en su momento, lo que no siempre resultaba creíble, según advertía en 1806 el visitador del monasterio de Penamaior, al revisar las cuentas del libro de panera correspondientes a la cosecha de 1805: "El alcance", dice, "es ilegal y en parte imaginario, por constar y formarse de algunas deudas cuya seguridad se ignora o que tal vez saldrán fallidas"26.

El volumen cambiante de las deudas está, por tanto, detrás de la fluctuación de las cantidades anotadas como alcance. Pero también parece haber cambios en la política de ventas de las instituciones, cada vez menos inclinadas a efectuar almacenamientos ocasionales en las diversas administraciones, y con tendencia a descentralizar las ventas en vez de recibir en la casa central volúmenes que sobrepasaban con mucho las necesidades del consumo. Para el caso del vino -que no permitía la "especulación" como los cereales- pueden servir de muestra las series de blanco y tinto de San Clodio de Leiro. (vid. cuadro 9, en la página siguiente)

De vino blanco, comercializado en su casi totalidad, apenas se guardan existencias para después de abril, fecha ya señalada de la realización de los balances, y en los tres primeros meses del año se vende en torno al 90 por cien de las entradas, pues los frailes no las consumen. Al contrario, los alcances de tinto son muy elevados hasta 1730 y después descienden hasta quedar establecidos en cantidades anuales fijas, las que la comunidad consideran necesarias hasta que empiece el gasto de vino nuevo. A diferencia de lo que sucedía con los cereales de la panera, los valores referidos al vino tinto están muy influidos por la drástica reducción de las entradas de la bodega -debido a que la granja de A Grova deja de remitir vino- y por el alza del consumo ordinario, lo

25 Así se dice, por ejemplo, en abril de 1671: "quedan de alcance final de centeno catorce mil ochenta y seis celemines y tres cuartos, que reducidos a fanegas hacen siete mil cuarenta y tres fanegas y tres octavos; quedan en ser en la panera mil doscientos y treinta y dos celemines, y en deudas cobrable según las condiciones de los foros queda lo restante [12.854,75 cls.], y que no han podido pagar los foreros por haber sido largo el invierno y no se poder maxar el pan", Arquivo do Reino de Galicia, Monasterios, libro 19, IV/1671.

26 Archivo Histórico Nacional de Madrid, Clero, libro 6161, cuentas de abril de 1806; además el padre panero había inflado el gasto de los animales y familia monástica, y no computara como ventas los arriendos de las rentas de varios lugares. 


\section{Cuadro 9}

Alcances, ingresos y empleo del vino blanco y tinto de la bodega de San Clodio. Medias anuales en moyos de 145 litros

\begin{tabular}{|l|c|c|c|c|c|c|}
\hline \multirow{2}{*}{ Años } & \multicolumn{7}{|c|}{ Blanco } \\
\cline { 2 - 7 } & 1. Alcance & 2. Recibo teórico & 3. Vendido & 4. Gasto total & $\% 1 / 2$ & $\% 3 / 4$ \\
\hline $1670-79$ & 15,90 & 276,75 & 254,90 & 263,25 & 5,7 & 96,80 \\
\hline $1680-89$ & 22,20 & 210,30 & 192,05 & 216,75 & 10,6 & 88,60 \\
\hline $1690-99$ & 8,35 & 242,30 & 224,50 & 241,35 & 3,4 & 93,00 \\
\hline $1700-09$ & 26,90 & 208,80 & 185,50 & 210,30 & 12,9 & 88,20 \\
\hline $1710-19$ & 18,25 & 221,25 & 194,25 & 214,25 & 8,2 & 90,70 \\
\hline $1720-29$ & 18,50 & 237,75 & 202,20 & 227,60 & 7,8 & 88,80 \\
\hline $1730-39$ & 22,25 & 187,15 & 174,90 & 203,90 & 11,9 & 85,80 \\
\hline $1740-49$ & 5,50 & 210,90 & 189,90 & 211,10 & 2,6 & 90,00 \\
\hline $1750-59$ & 6,20 & 199,40 & 158,00 & 199,20 & 3,1 & 79,30 \\
\hline $1760-69$ & 7,90 & 211,40 & 182,10 & 211,20 & 3,7 & 86,20 \\
\hline $1770-79$ & 6,70 & 222,60 & 195,10 & 223,10 & $3,-$ & 87,40 \\
\hline $1780-89$ & 6,00 & 231,40 & 204,70 & 231,10 & 2,6 & 88,60 \\
\hline $1790-99$ & 6,20 & 217,25 & 189,50 & 217,50 & 2,9 & 87,10 \\
\hline $1800-09$ & 6,00 & 210,15 & 178,90 & 210,25 & 2,9 & 85,10 \\
\hline $1810-14$ & 35,00 & 159,15 & 109,60 & 147,95 & $22,-$ & 74,10 \\
\hline
\end{tabular}

\begin{tabular}{|l|c|c|c|c|c|c|}
\hline \multirow{2}{*}{ Años } & \multicolumn{7}{|c|}{ Tinto } \\
\cline { 2 - 7 } & 1. Alcance & 2. Recibo teórico & 3. Vendido & 4. Gasto total & $\% 1 / 2$ & $\% 3 / 4$ \\
\hline $1670-79$ & 584,00 & 552,25 & 488,60 & 562,25 & 105,6 & 86,90 \\
\hline $1680-89$ & 484,90 & 486,50 & 382,40 & 494,80 & 99,7 & 77,30 \\
\hline $1690-99$ & 548,80 & 537,75 & 444,80 & 549,00 & 102,1 & 81,00 \\
\hline $1700-09$ & 330,50 & 339,15 & 230,60 & 340,25 & 97,4 & 67,80 \\
\hline $1710-19$ & 298,15 & 407,40 & 283,80 & 429,40 & 73,2 & 66,10 \\
\hline $1720-29$ & 345,25 & 399,50 & 285,10 & 408,50 & 86,4 & 69,80 \\
\hline $1730-39$ & 166,75 & 228,00 & 116,00 & 244,50 & 73,1 & 47,40 \\
\hline $1740-49$ & 161,10 & 242,90 & 111,50 & 242,10 & 66,3 & 46,10 \\
\hline $1750-59$ & 145,70 & 225,50 & 90,70 & 226,00 & 64,6 & 40,70 \\
\hline $1760-69$ & 134,65 & 266,75 & 99,90 & 269,20 & 50,5 & 37,10 \\
\hline $1770-79$ & 128,00 & 270,10 & 81,70 & 258,40 & 47,4 & 31,60 \\
\hline $1780-89$ & 143,00 & 293,50 & 123,00 & 288,90 & 48,7 & 42,60 \\
\hline $1790-99$ & 150,00 & 285,75 & 105,10 & 285,80 & 52,5 & 36,80 \\
\hline $1800-09$ & 150,00 & 300,70 & 121,00 & 300,70 & 49,9 & 40,20 \\
\hline $1810-14$ & 150,00 & 244,00 & 43,60 & 221,75 & 61,5 & 19,70 \\
\hline Fuente: Elaboración a partir del Arquivo Histórico Provincial de Ourense, Clero, libro 745. & \\
\hline
\end{tabular}


que provocó una severísima caída de las ventas ${ }^{27}$. La reducción de los alcances deriva de la que afecta a las entradas y probablemente también de que los frailes tendieron a vender el vino en fechas tempranas, sin esperar a comienzo del verano, en un contexto en el cual la competencia en el mercado se iba endureciendo. No parece plausible en este caso que los elevados remanentes de fines del XVII deriven sólo de deudas, pues entonces deberían aparecer igual en el vino blanco; tampoco de stocks guardados regularmente de un año para otro, lo que resultaba temerario por las características del vino gallego, difícil de conservar ${ }^{28}$. Por lo mismo ha de tratarse de existencias destinadas al consumo ordinario y a ventas realizadas desde el 15 de abril hasta verano a mercaderes que se acercaban al cenobio, pues en la segunda mitad del XVIII los monjes llevaban en ocasiones el vino a Santiago y alquilaban un local para venderlo.

\section{Deudas y ventas: economía campesina y economías rentistas}

Si las cantidades que los monjes anotan en el cargo y descargo como alcances están formadas en proporciones variables, que pocas veces podemos conocer, por verdaderos stocks y por deudas, hay que concluir, a partir de los datos que han quedado expuestos, que los campesinos pagaban puntualmente las rentas y diezmos de maíz y que los padres paneros y monjes granjeros lo vendían con relativa facilidad entre la cosecha y mediados de abril, momento de cierre del ejercicio. El maíz, en efecto, se presta peor al almacenamiento que el trigo, centeno y mijo, que removidos de modo regular en paneras secas y ventiladas podían aguantar unos dos años (no sin riesgos, por las características climáticas de Galicia) ${ }^{29}$. Esta circunstancia ayuda a explicar, al menos en parte, la ausencia de remanentes de cereal americano, pero no de deudas, pues ninguna disposición impedía a los colonos pagar los atrasos de maíz a las valías, según hacían con las demás rentas de los foros y arriendos estipuladas en otros productos.

27 Hasta 1738 el gasto ordinario de la comunidad se situó en torno a los 98 moyos; subió hasta los 130 y aunque en los años siguientes descendió un poco, en 1759 ascendió a 141 moyos, en 1760 a 156 y en 1768 a 168 moyos. Arquivo Histórico Provincial de Ourense, Clero, libro 745.

28 En los libros de bodegas consultados no encontramos ni una sola referencia a la fabricación de aguardiente (sí en pazos, para consumo propio). El vino viejo podía mezclarse, pero no parece que esta práctica se realice con grandes cantidades. La misma constatación en RIONEGRO FARIÑA, I.: La estructura económica del Císter..., con datos de diversos prioratos vitícolas y de bodegas, posteriores a 1750 .

29 En Castilla el cereal podía aguantar unos tres años, como máximo, cfr. SEBASTIÁN AMARILLA, J.A.: Agricultura y rentas monásticas....También se ocuparon de la cuestión y de las posibilidades reales o teóricas de almacenar y especular B. Yun y E. Llopis, en una polémica mantenida en las páginas de la revista de Historia Económica, núm. 3 (1988), pp. 461-477; 2 (1989), pp. 461-477; 1 (1990), pp. 173-185 y 187-190. Vid. asimismo la obra clásica de ANES, G.: Las crisis agrarias en la España Moderna, Madrid, Taurus, 1970, y la monografía de ÁLVAREZ VÁZQUEZ, J.A.: Rentas, precios y crédito en Zamora en el Antiguo Régimen, Colegio Universitario de Zamora, 1987. 
La naturaleza proporcional de las cargas satisfechas en maíz en muchos prioratos del litoral y valles (caso de los Ribeiros) facilitaba su pago en los años de carestía, de acuerdo con lo que ya quedó advertido; también el hecho de tratarse de un producto cuya importancia en valores absolutos y relativos se fue incrementando dentro del sistema de cultivos, pero que se consumía a menudo mezclado con centeno, y al escasear éste, si los campesinos se veían obligados a contraer atrasos, optarían por no satisfacer aquel cereal que más apreciaban como alimento. Sin embargo, quedan varios problemas por resolver: podemos apuntar algunas de las posibles causas de las menguadas deudas de rentas de maíz, no tanto las razones de su aparente fácil comercialización, probablemente realizada entre campesinos empobrecidos, que apenas podían consumir cereales que gozaban de una superior estima social (el centeno, y no digamos ya el trigo $)^{30}$. Cabe suponer, en todo caso, que más que ventas en mercados rurales o urbanos, lo que ocurre en la realidad es que los propios colonos se quedan en muchos casos con el maíz, pagándolo a las valías, de modo que las cantidades justificadas como vendidas serían a menudo cobradas en dinero, práctica muy extendida, de ahí que en ocasiones los mayordomos y padres paneros hablen de cereal "vendido o cobrado", eso sí, sin especificar en la mayoría de las ocasiones unas y otras cantidades ${ }^{31}$.

La práctica de incluir en la misma partida el producto vendido y cobrado enmascara otra que la acompaña: las rentas atrasadas, percibidas a las valías del año al que correspondían, figuran como cantidades vendidas el año en que efectivamente se cobraron (antes formaban parte del alcance). Esto solo puede comprobarse en algunos libros de cuentas que, ocasionalmente, dan más información de la habitual. Así, a diferencia de los de otras administraciones, los del priorato de las Cascas tienen la ventaja de aclarar, durante la primera mitad del XVIII, el año al que pertenecen las rentas vendidas en un determinado ejercicio, esto es, la cadencia con la que los monjes granjeros van recuperando los atrasos. A partir del análisis de los datos sabemos que

30 La superior estima del centeno frente al maíz, como cereal de consumo, está ampliamente atestiguada en los propios libros de cuentas de monasterios y pazos, en instrucciones sobre alimentación de criados y en testimonios etnográficos. Recogí alguna noticia al respecto en La vida cotidiana en la Galicia del Antiguo Régimen, Barcelona, Crítica, 1994, p. 139.

31 De hecho, los precios que certificaban las autoridades locales servían para pagar rentas, atrasadas o no. Vid. Eiras Roel, A. y Usero, R.: "Los precios de los granos...”. J. M. PÉREZ GARCÍA advirtió asimismo, hace años, que en las Rías Bajas el sistema de cultivos del siglo XVIII tenía poco que ver con la estructura de las rentas monásticas, fijadas en parte en cereales que ya apenas se cultivaban; la situación sólo se explica, como él bien señala, porque muchas rentas de mijo, por ejemplo, se pagaban en dinero; vid. de este autor: Un modelo de sociedad rural de Antiguo Régimen en la Galicia costera, Universidade de Santiago, 1979, p. 296 y ss., y del mismo, sobre la evolución del sistema agrario, "Aproximación al estudio de la penetración del maíz en Galicia”, en EIRAS ROEL, A. et alii.: La historia social de Galicia en sus fuentes de protocolos, Universidade de Santiago, 1981, p. 117 y ss. 
las cantidades, bastante elevadas según ya hubo ocasión de ver, que aparecen asentadas como alcance no son otra cosa que deudas consideradas cobrables, y que se dan por vendidas el ejercicio en que los campesinos las pagan a las valías del año al que correspondían. Esto significa que en los libros de los demás prioratos y paneras figura revuelto lo efectivamente comercializado con lo cobrado en dinero, y, lo que tiene una mayor importancia, que en el mismo balance se mezclan cantidades vendidas a precios diferentes, no sólo por el fenómeno de la estacionalidad, sino por ser de años distintos, a veces bastante alejados ${ }^{32}$. La conclusión es que no está garantizada, ni mucho menos, la homogeneidad de los abundantes datos de precios que aparecen en los libros de cuentas, utilizados con profusión por los investigadores. Los valores resumidos pertenecientes al mencionado priorato por decenios figuran en el cuadro siguiente:

Cuadro 10

Centeno vendido o cobrado por el priorato de las Cascas.

Medias anuales en fanegas

\begin{tabular}{|l|c|c|c|c|c|}
\hline Años & 1. Del año/cosecha & $\mathrm{Rs} / \mathrm{Fg}$ & 2. Atrasos & $\mathrm{Rs} / \mathrm{Fg}$ & \% de atrasos \\
\hline $1700-09$ & 268,50 & 12,20 & 140,80 & 13,20 & 34,3 \\
\hline $1710-19(1)$ & 230,20 & 14,35 & 48,33 & 17,28 & 17,4 \\
\hline $1720-29$ & 286,75 & 12,24 & 125,50 & 10,42 & 30,4 \\
\hline $1730-39$ & 322,25 & 17,60 & 68,10 & 15,50 & 17,4 \\
\hline $1740-49$ & 230,47 & 18,08 & 213,50 & $18,-0$ & 48,1 \\
\hline $1750-57$ & 313,70 & 22,08 & 130,30 & 19,56 & 29,1 \\
\hline Media & 275,55 & 15,94 & 123,36 & 14,88 & 30,9 \\
\hline $\begin{array}{l}\text { (1) Sin 1716y 1717, porque la fuente es poco clara. } \\
\text { Fuente: Elaboración a partir del Arquivo do Reino de Galicia, Monasterios, libros 237 y 238. }\end{array}$ \\
\hline
\end{tabular}

Cerca de un tercio del centeno que figura como vendido en un determinado ejercicio es, en realidad, pan procedente de atrasos cobrados a las valías. Puede verse que las oscilaciones de decenio a decenio son muy grandes, y en 1740-49 el 50 por cien del centeno formalmente comercializado deriva de pagos realizados por colonos que en su momento no pudieron hacer frente a las rentas forales. Los precios medios del cereal vendido o cobrado a dinero en el año en que fue cosechado y del cobrado a las valías no se distancian mucho cuando los cálculos se hacen por decenios, pero sí cuando se realiza un análisis de carácter anual, sin duda más significativo. Así, las rentas correspondientes a la cosecha de 1702 se vendieron a 20 reales, y los atrasos se cobraron a 8; para las de 1703 los valores fueron, por el mismo orden, de 23 y 18,63; para las de 1704 de 10,52 y 19,6; para las de 1705 de 6 y 13,74, y los ejemplos de

32 Cuando, como sucede a menudo, los monjes granjeros o padres paneros se limitan a decir que vendieron un determinado número de fanegas, indicando solo el precio global o promedio por fanega ("unas con otras valieron a....."). 
situaciones diferentes, en las que el precio medio de los atrasos cobrados a las valías ora es superior ora inferior al del propio año, se repiten ${ }^{33}$.

Los monjes granjeros de las Cascas suelen percibir los atrasos a los valores fijados por las justicias locales, que pueden ser más altos o más bajos que los precios correspondientes al año en que las deudas se cobran. En el ejercicio de IV/1706 a IV/1707, por ejemplo, el administrador percibió 82 fanegas de atrasos, unas valoradas a 4 reales, otras a 10 y otras a 12 (24 de 1697 y 1698) $)^{34}$. De todas formas, aunque no sea la tónica, no faltan los casos en los que el cereal adeudado lo satisfacen los campesinos a precios muy distintos, o al menos inferiores a los que el fraile pudo comercializar el que le llevaron los colonos que cumplieron puntualmente con sus obligaciones ${ }^{35}$. Y es que en un contexto en el que era necesario tratar de un modo individual con colonos cuya situación económica variaba y también sus relaciones con la comunidad monástica, las leyes, en teoría impersonales, del mercado estaban condicionadas por múltiples factores de orden social, y los precios fijados con carácter general para una jurisdicción debían modificarse y acomodarse a variadas circunstancias familiares y locales. Las oscilaciones que dentro del mismo año cosecha registran los valores a los que el centeno fue cobrado o vendido no parece que sean ajenas a los factores mencionados, aparte de la indudable influencia de la estacionalidad ${ }^{36}$.

La posibilidad de satisfacer más adelante las cargas forales correspondientes a una cosecha, a los precios establecidos por las justicias, constituía en principio una solución momentánea para colonos agobiados por falta de pan o por otros accidentes, y que podían posponer así durante uno o varios años el pago de las rentas. Pero este expediente no estaba exento de efectos perversos, porque los débitos habían de pagarse en dinero, en principio, a los precios del año en que fueran contraídos: si el campesino dejara de pagar 10 fanegas con motivo de una cosecha estéril, que

33 En los ejercicios correspondientes a 1730, 1731, 1738, 1739, 1743, 1748, 1751, 1757, etc, aparecen también notorios contrastes.

34 Los ejemplos podían alargarse: en IV/1708-IV/1709, cobra atrasos a 3,5, 4, 6 y 10 rs. la fanega; en IV/1710-IV/1711 a 4,9 y 18 reales; en IV/1730-IV/1731 a 5 y 9; en IV/1740-IV/1741 a 7, 8, 12 y 14 reales; en IV/1744-IV/1745 a 4, 7,5, 8 y 14; Arquivo do Reino de Galicia, Monasterios, libro 238, cuentas de los ejercicios mencionados.

35 Así, en el ejercicio de 1713 el monje granjero cobra 12,5 fanegas del de 1712 a 8 reales, cuando ese año vendieron 356 fanegas a 9 y 10 reales; en 1706 el centeno valió a 4,5 y 5 reales, y los atrasos fueron percibidos a 4. Hay ejemplos inversos también (en 1702 se vendieron 502 fanegas de la cosecha a 10 reales, y 262 que pagaron los colonos al año siguiente les fueron tasadas a 11,5). Ib.

36 A. I. FERNÁNDEZ GONZÁLEZ, en su tesis doctoral inédita ("A Fiscalidade eclesiástica en Galicia, 1750-1850", Universidade de Santiago, Depto. de Historia e Institucións Económicas, 1995) aporta numerosos testimonios de como los "monjes granjeros" trataban de modo diferente a unos y otros colonos, según la docilidad que éstos mostraban a la hora de pagar las rentas y de respetar los privilegios monásticos. Vid. también, del mencionado autor: "Los grupos de poder local en Galicia, 1750-1850", Noticiario de Historia Agraria, 9 (1995), pp. 129-153. 
provocara un alza de precios, tendría que vender 15 ó 20 un año de abundancia para reunir el dinero que adeudaba. La situación era inversa cuando el empeño procedía de impagos correspondientes a años de precios bajos, si bien los colonos no andarían sobrados de excedentes para comercializarlos en épocas de fuertes alzas. En definitiva, las deudas arrastrarían a las economías campesinas a participar, cada vez más intensamente, en un "comercio forzado", esto es, a vender más cuando los precios eran menos remuneradores ${ }^{37}$. El análisis de la secuencia del pago de atrasos en el priorato de las Cascas deja ver que las cantidades más voluminosas se saldan en años de precios medios o ligeramente altos, y rara vez en momentos de mínimos, prueba de que los campesinos lograron evitar, al menos parcialmente, las ataduras del "comercio forzado", circunstancia a la que pudo contribuir la diversificación de cultivos, y por tanto de recursos, de las economías familiares.

Al margen de lo que venimos exponiendo, la contabilidad del mencionado priorato de Sobrado y la de la propia panera abacial -si bien menos precisa- permiten comprobar hasta que punto los procesos de comercialización se hallaban condicionados por las deudas, pues los alcances están compuestos básicamente por atrasos cobrables, asentados como recibidos y vendidos el año de su paga, de modo que los ejercicios de ventas más voluminosos no son fruto de una estrategia de almacenamiento, sino del simple resultado de la recuperación de débitos, a precios muy variados. Entre la teoría y la práctica mediaba a menudo un abismo, y las economías señoriales estaban en cierto modo atadas por la dinámica de las pequeñas explotaciones, cuya capacidad de pago marcaba el ritmo de las entradas de especies y de numerario de las instituciones y casas rentistas.

En la panera de Sobrado, por la información existente desde fines del XVII a mediados del XVIII, se comprueba que lo habitual era que en un ejercicio figuren como vendidas cantidades a precios muy diferentes, pues parte de ellas son atrasos de años pasados. En el balance cerrado en abril de 1699, por ejemplo, el padre panero anota que vendió centeno de las cosechas de 1697 y 1698, y recuperó atrasos de 1687 en adelante, unos a 4 reales/fanega y otros a 5, 6, 8, 10, 11 y 12 reales. Otras veces se dan como vendidas cantidades empleadas en pagar jornales, según sucede en los años cosecha 1713 (276 fanegas), 1715 (300 fanegas), 1716 (909 fanegas), 1717 (206,5) y $1719(500)^{38}$. Cobros en dinero, sean o no del mismo año, y otras operaciones se esconden por tanto detrás de aparentes ventas en mercados, lo que tiene su lógica, pues

37 De acuerdo con el modelo formulado por BADHURI, A.: La estructura económica de la agricultura atrasada, México, FCE, 1987.

38 Los datos correspondientes a la panera de Sobrado cubren de 1693 a 1749, a partir de ellos puede comprobarse como las ventas oscilan de menos de 1.000 fanegas al año a más de 4.000, con los ingresos estabilizados; pero los ejercicios con ventas elevadas son épocas de recuperación de atrasos (los 
para los mayordomos lo fundamental es que en lugar de la renta en especie habían recibido -o ahorrado en el caso de los jornales en especie- dinero.

$\mathrm{Si}$ en los prioratos y parcialmente en las paneras los alcances estaban constituidos por atrasos cobrables, su descenso, en ocasiones espectacular, desde 1730/50 hasta entrado el siglo XIX significa en principio que los campesinos fueron capaces de pagar con mucha mayor puntualidad las rentas. Este hecho nos parece de gran relevancia, aunque de no fácil explicación: la ya mencionada diversificación de recursos de las economías familiares, con el avance de los cereales de primavera y luego de las patatas en el interior (rara vez mencionadas en las contabilidades); los progresos en la comercialización del ganado vacuno; el desarrollo de una industria textil rural, que alcanzó una gran importancia en determinadas comarcas; la intensificación de la emigración estacional y plurianual, con el aporte de las oportunas remesas a las familias afectadas ${ }^{39}$. Todo ello amplió y reforzó las fuentes de ingresos de los campesinos, en especial con entradas en numerario, lo que resulta decisivo en el tema que nos ocupa, pues las rentas, fijadas en especie, se pagaban a menudo en dinero; desde luego los atrasos, y a veces las del propio año, y los padres paneros y los monjes granjeros solían asentar como vendido formalmente el cereal cobrado a las valías -según quedó advertido-. La relación existente entre pago de atrasos e ingresos en numerario, al margen de los generados por la pequeña explotación, queda de manifiesto en varias cartas enviadas al conde de Amarante desde el partido de Xobre, cerca de Caramiñal, en la década de 1790: "los más de los caseros se lamentan de lo crítico de la estación para pagar deudas, porque en este tiempo no tienen un cuarto hasta agosto que venden cuatro ferrados de trigo (...) En la actualidad van muchos en Castilla, y principalmente en junio casi todos, y no vuelven hasta el agosto, a cuyo tiempo podian exigírseles las rentas del 91 y 92 [1791 y 1792], pues entonces además del trigo tienen algún dinero y les es menos sensible el apronto", decía en una misiva en mayo de 1793, y el año anterior un colono que se hallaba "rigurosamente executado" por atrasos, argumentaba que una de las causas de los impagos derivaba de que llevaba

datos referidos a la panera proceden de la información del libro de caja, Arquivo do Reino de Galicia, Monasterios, libro 447).

39 Sobre la importancia, fundamental en algunas comarcas, de la industria textil rural, vid. CARMONA, J.: El atraso industrial de Galicia. Auge y liquidación de las manufacturas textiles, 1750-1905, Barcelona, Ariel, 1991; y SAAVEDRA, P.: Economía, Política y Sociedad en Galicia: la provincia de Mondoñedo, 1480-1830, Madrid, Xunta de Galicia, 1985, pp. 344-376. Sobre la emigración, aparte de otros trabajos realizados o impulsados por A. Eiras Roel, vid., EIRAS ROEL, A. y REY CASTELAO, O.: (Eds.), Migraciones internas y medium-distance en la península Ibérica, 1500-1900, Santiago, Xunta de Galicia/CIDH, 1995, con varios trabajos sobre Galicia. 
para dos años "bien enfermo y baldado de un reumatismo que me impide ganar por los veranos en el Reino de Castilla"40.

Aparte de las rentas atrasadas satisfechas después a las valías, estaban las que los campesinos pagaban puntualmente de acuerdo con las condiciones establecidas en los foros, pero que las pagaban también en dinero, fenómeno más o menos extendido según las comarcas y las épocas. La información correspondiente a la panera de Sobrado resulta de nuevo muy ilustrativa en este punto, pues el libro de estado distingue desde mediados del XVIII el cereal vendido, después de haber sido cobrado antes en especie, del "entregado en memoriales" con relaciones de colonos que pagaban a las valías. Surge en ocasiones la duda de si estos memoriales entregados en la cillería correspondían a cantidades realmente cobradas o son simples relaciones de deudores: dado que se asentaban en el libro de caja como entrada efectiva de numerario cabe colegir que en la mayoría de los casos habían sido $\operatorname{cobrados}^{41}$. De cualquier modo la desproporción entre las rentas en especie y los cobros reales o esperados a las valías parece evidente hasta comienzos del XIX:

\section{Cuadro 11}

Evolución de las cantidades de centeno cobradas en especie y luego comercializadas y de las cobradas a las valías por la panera del monasterio de Sobrado. Medias anuales en fanegas

\begin{tabular}{|c|c|c|c|c|}
\hline Años cosecha & $\begin{array}{c}\text { 1. Cobrado en } \\
\text { especie y vendido }\end{array}$ & $\begin{array}{c}\text { 2. Cobrado a las valías } \\
\text { ("entregado en cillería") }\end{array}$ & $\begin{array}{c}3 . \\
\text { Total }\end{array}$ & $\% 1 / 3$ \\
\hline $1743-1755$ & 70,25 & $1.899,25$ & $1.969,50$ & 3,60 \\
\hline $1758-1770$ & 43,25 & $2.029,50$ & $2.072,75$ & 2,10 \\
\hline $1771-1786$ & 115,25 & $1.798,50$ & $1.913,75$ & 6,00 \\
\hline $1788-1798$ & 546,00 & $1.577,50$ & $2.123,50$ & 25,70 \\
\hline $1799-1810$ & 457,75 & $1.537,75$ & $1.995,50$ & 22,90 \\
\hline $1811-1818$ & 748,00 & $1.573,50$ & $2.321,50$ & 32,20 \\
\hline $1823-1831$ & 953,50 & $1.265,25$ & $2.218,75$ & 43,00 \\
\hline
\end{tabular}

Resulta asombroso que hasta la década de 1780 el monasterio apenas cobrase en especie otro cereal que el destinado a consumo ordinario y demás gastos de funcionamiento, en tanto "vendía" a los propios colonos (pues no otra cosa era cobrarlo a las valías) alrededor del 50 por cien de las entradas teóricas de cada año ${ }^{42}$. Dicho de otra forma, los padres paneros no llevan al mercado excedentes, pues éstos los ad-

40 Archivo de la Fundación Ducal de Medinaceli (Sevilla), secc. Amarante, leg.92, correspondencia sin numerar, cursiva nuestra.

41 Con todo, la cuestión no está del todo clara y no es fácil de resolver.

42 Pues en el cuadro solo se comparan las cantidades vendidas en especie y las cobradas, y se prescinde de las percibidas en especie y destinadas al consumo humano y animal. 
quieren sus mismos productores. Es en la última década del siglo cuando se perciben cambios de relieve y se va consolidando la tendencia a cobrar en especie y vender, lo que en vísperas de la exclaustración se hace casi con la mitad del centeno de la panera destinado a la comercialización. Ello significa que las economías campesinas de la comarca estuvieron en condiciones de prescindir de cantidades de cereal cosechadas que antes retenían y que, a la vez, un relativo crecimiento de la población urbana (o incipientes procesos de urbanización vinculados a veces a las ferias) posibilitó la absorción de excedentes físicos cada vez más voluminosos. Tiene interés destacar que las cantidades de centeno satisfechas en especie crecen tanto en la fase de precios altos (1788 a 1817), como en la de precios bajos (1823-31), cuando de acuerdo con la evolución relativa de la cotización de los diversos productos (cereales y ganado, especialmente), al campesino le hubiera sido ventajoso, en teoría, pagar a las valías.

No puede generalizarse a las economías rentistas y campesinas de todo el Reino la tendencia que marcan con claridad los datos de la panera de Sobrado. Hay que reparar en que el monasterio está situado en una comarca de transición al interior, productora de centeno y en la que la expansión del cultivo de las patatas tuvo que relativizar la función del cereal en la alimentación, permitiendo a los colonos entregar en especie cantidades que antes satisfacían a las valías. En las comarcas del litoral y valles prelitorales, y en las de viticultura, la situación del campesinado era más apurada en la etapa final del Antiguo Régimen, lo que explica también que el problema de las deudas afecte, de modo desigual, en el primer tercio del siglo XIX, a las instituciones y casas rentistas, según queda de manifiesto en los libros de caja.

En las administraciones del conde de Amarante se advierten situaciones diferentes en la forma del pago de las rentas, con tendencias diversas en la casa de Oca y en la que daba título al condado:

Cuadro 12

Centeno cobrado a las valías y en especie en Oca, en algunos años del XVIII. En fanegas

\begin{tabular}{|c|c|c|c|}
\hline Año & En especie & A las valías & \% a las valías \\
\hline 1745 & 132,00 & 145,25 & 52,40 \\
\hline 1746 & 116,00 & 161,50 & 58,20 \\
\hline 1751 & 140,18 & 130,63 & 48,30 \\
\hline 1752 & 146,25 & 139,00 & 48,70 \\
\hline 1795 & 249,70 & 28,50 & 10,20 \\
\hline 1796 & 244,63 & 32,75 & 11,80 \\
\hline \multicolumn{2}{|l}{} \\
\hline \multicolumn{2}{|l}{} \\
\hline
\end{tabular}


De una situación en la cual los campesinos pagaban en dinero alrededor del 50 por cien de las rentas de centeno pertenecientes al conde de Amarante, se pasa a otra en la que los señores cobran casi todo en especie, una tendencia con parecidos a la vista en Sobrado, sólo que más acentuada. Pero en alguna medida los cambios pudieron deberse al incremento del consumo ordinario a raíz de la estancia frecuente de los condes en el pazo en el último cuarto del siglo XVIII y a la realización de obras, lo que llevaría al mayordomo a presionar a los colonos para que pagasen en especie; tampoco hay que olvidar que los pagos a las valías estaban muy relacionados con los atrasos, y éstos a su vez con elevados alcances, que descienden considerablemente desde mediados del XVIII. Así sucedió en la administración de la casa de Xunqueiras, en donde se produce una extraordinaria acumulación de deudas a fines del XVIII y primeros años del XIX, y una recuperación desde el trienio. Pues bien, en la década de 1770 alrededor de un 90-95 por cien de las rentas de trigo, centeno y maíz se cobran en dinero, situación que se invierte en las décadas de 1820-3043.

En la administración de Amarante, en la comarca interior y centenera de la Ulloa, la tendencia que se registra en la segunda mitad del XVIII es a aumentar las cantidades de centeno de foros pagadas en dinero, lo que contrasta con lo visto para Sobrado o para Oca, pero cuadra con lo documentado a propósito de la monetización creciente de las economías campesinas.

Si en la segunda mitad del XVIII alrededor del 50 por cien de las rentas forales se cobraban en dinero, hay que tomar en consideración este hecho, absolutamente fundamental para entender el funcionamiento de las economías familiares, y su creciente dependencia del mercado, fuese éste forzado o no. La proliferación de ferias y mercados, que en el curso del siglo XVIII llegan a triplicarse en Galicia (y en general en la España cantábrica), no puede explicarse sin atender a los mecanismos de reproducción de las pequeñas explotaciones, por cuanto las reuniones mercantiles tienen un carácter rural y nacen a menudo por iniciativa campesina, y una de sus finalidades es facilitar la venta de ganado y lienzos para poder así allegar recursos para pagar las rentas forales a las valías ${ }^{44}$. A la postre, la incidencia de las rentas percibidas por los estamentos privilegiados sobre explotaciones insuficientes terminó por obligar a las familias campesinas a diversificar sus ingresos, consolidando una formación

43 Vid. el exhaustivo estudio de IGLESIAS BLANCO, A.S.: A casa de Xunqueiras nos séculos XVIII e XIX. Contribución ó estudio das economías fidalgas, Concello de Valga (Pontevedra), 2004, especialmente tablas 2-4, en pp. 247-251.

44 SAAVEDRA, P.: "Feiras, rendas provinciais e motíns na Galicia de finais do XVIII", en $A$ Facenda Real na Galicia do Antigo Réxime (As rendas provinciais), Santiago, EGAP, 1993, pp. 155 y ss. Un mapa de las localidades con ferias y mercados en GARCÍA LOMBARDERO, J.: La agricultura y el estancamiento económico de Galicia en la España del Antiguo Régimen, Madrid, Siglo XXI, 1973, pág. 66 (y apéndice, pp. 180-194, una relación nominal). 


\section{Cuadro 13}

Centeno cobrado vendido en especie y cobrado a las valías en la casa de Amarante. Medias anuales en fanegas

\begin{tabular}{|l|c|c|c|}
\hline Años & Vendido en especie* $^{*}$ & Cobrado & \% Cobrado \\
\hline $1753-57$ & 404,75 & 41,50 & 9,3 \\
\hline $1765-66$ & 192,00 & 242,50 & 55,8 \\
\hline $1774-79(1)$ & 251,75 & 109,75 & 30,4 \\
\hline $1780-89$ & 206,25 & 221,75 & 51,8 \\
\hline $1791-99$ & 212,25 & 208,50 & 49,6 \\
\hline $1800-02$ & 142,50 & 222,50 & 61,0 \\
\hline
\end{tabular}

Fuente: Archivo Fundación Ducal de Medinaceli, Amarante, leg.

Fanega de 5 ferrados

(1) Sólo años 1774, 1778 y 1779.

* A veces el centeno cobrado en especie es algo más, pues solo se comparan cantidades vendidas y cobradas; pero el consumo es muy bajo, al no residir en el pazo los señores.

social de pequeños productores y de rentistas profundamente condicionada por la dependencia del mercado. A este respecto, Rafael Domínguez habló del "campesinado adaptativo" del Cantábrico, para enfatizar la "pluriactividad campesina"45, pero prestando escasa atención a la función clave que tiene la renta en la extensión de las relaciones mercantiles, al menos en Galicia.

Mediante la diversificación de recursos, la pequeña explotación campesina garantizó su viabilidad, y al tiempo contribuyó a la solidez de las economías rentistas, por paradójico que esto pueda parecer. Una parte de los cuantiosos excedentes de foros, arriendos y diezmos acabaron siendo comprados por sus mismos productores, gracias a la obtención del numerario en actividades varias. Los mecanismos de comercialización de unos ingresos que, por su volumen, no podían ser absorbidos por los mercados urbanos, quedan en cierto modo al descubierto en cuanto se profundiza en la forma de pago de las rentas y en el problema de los atrasos y de su liquidación (cuestión que, como quedó de relieve, sólo puede conocerse mediante el análisis detallado de la evolución de los alcances, que figuran en el cargo y el descargo de los balances de cada ejercicio).

Los mercados urbanos ni siquiera podían absorber las cantidades cobradas en especie y vendidas por los mayordomos. Las escasas noticias que hay sobre los mecanismos de comercialización real de cereales apuntan a que las ventas directas a personas que se acercaban a las tullas coexistían con el recurso a las ferias y mercados, y en todo caso, las transacciones afectan a pequeñas cantidades, y por lo mismo implican a muchos compradores. Entre la correspondencia de los condes de Amarante quedan

45 Cfr. DOMÍNGUEZ MARTÍN, R.: El campesinado adaptativo. Campesinos y mercado en el norte de España, ya citado, que insiste mucho en las formas de contacto de los campesinos con el mercado. 
algunas cartas instando a los mayordomos a que estén atentos a la mejor sazón para vender el pan: en 20 de febrero de 1735 la condesa le encomendaba al encargado de la administración de Amarante que "cuando Vmd. contemple tendrá mejor salida y precio el pan de Camba y Gián podrá despacharlo mirándolo como cosa suya”, y en marzo de 1738 le mandaba que "asista siempre en su casa, porque muchas veces sucede venir [alguien] a comprar, y no hallando quien lo despache luego se van a otras partes". A juzgar por la correspondencia, la comercialización se realizaba cuando se aproximaba la primavera, y cada mayordomo miraba de reojo lo que hacían los responsables de otras tullas que estaban en las proximidades y hacían competencia ${ }^{46}$.

De la fragmentación de las ventas quedan muestras elocuentes en la contabilidad de la casa de San Fiz y agregadas, pertenecientes en el XVIII a los Prado y Lemos, avecindados en Lugo. A diferencia de otros mayordomos, el de San Fiz anota los cereales que realmente cobra en especie -y no los teóricos-, de ahí que las cantidades fluctúen bastante de un año a otro, y especifica los diferentes precios a como los vendió, y en algunos años, el número de operaciones y los meses. Unas 175 fanegas de centeno de promedio vendió el administrador de 1760 a 1821, registrándose una media de seis-siete precios distintos en cada ejercicio, según ha señalado V. Migués ${ }^{47}$. Hay, no obstante, muchas más operaciones que precios diferentes: así, de los frutos de la cosecha de 1787 se vendieron 229,3 fanegas, en 71 operaciones (un promedio de 3,25 fanegas: la mayor operación afectó a 22 fanegas); al año siguiente para comercializar 105,6 fanegas de la tulla de San Fiz fueron necesarias 44 operaciones (media de 2,4 fanegas por venta); en 1789 se registran 101 transacciones para dar salida a 213,75 fanegas (tullas de San Fiz, Tarrío y Chantada), afectando la más voluminosa a 17,8 fanegas y la menor a 0,1 . Por fin, en 1790, aparecen 78 operaciones para despachar 210 fanegas (máximo de 21,6 y mínimo 0,2). Cuando se especifica la cronología de las ventas, se advierte que tienen lugar en el invierno y primavera siguiente a la cosecha: en los meses enero a marzo los frutos de 1788; de diciembre a mayo los de 1789; de enero a junio los de 1790, y de marzo a mayo los de 1791, sin que se perciba una clara tendencia a beneficiar las mayores cantidades a los precios más elevados ${ }^{48}$.

$* * *$

46 Así en febrero de 1787 el conde le escribía al mayordomo de Amarante que le parecía bien el precio de 5,15 rs. por ferrado (27,5 por fanega), pero que estuviese atento a un posible aumento, "si resultase de otras tullas". El año anterior el mayordomo bajara el precio inicial de 6,5 a 6,25 rs., lo que aprobó el conde: "mayormente estando asomados a una cosecha generalmente buena" (VI/1780); Archivo Fundación Ducal, secc. Amarante, leg. 77.

47 MIGUÉS, V.: As terras, as pousas, e os vinculeiros. A fidalguía galega na época moderna, SadaA Coruña, Ediciós do Castro, 2002, págs. 242-243 y 281-282. Sólo en el año cosecha de 1784 se vende todo el centeno a un mismo precio, mientras en 1769 aparecen 21 valores distintos y en 1799 figuran 20.

48 Arquivo do Reino de Galicia, Fondo de la familia Ozores, legs. 71 y 74. 
El problema de la comercialización de los excedentes agrarios percibidos por los estamentos privilegiados del Antiguo Régimen se abordó a menudo dando por supuesto que monasterios, cabildos catedralicios y casas nobles vendían año tras año a los precios más ventajosos, con frecuencia los que regían en los meses de soldadura. Bastaba para probarlo invocar la gran obra de E. Labrousse ${ }^{49}$. El análisis de los libros de cuentas de los cenobios cistercienses y de algunas familias hidalgas, pese a la información incompleta que ofrecen a menudo, permite afirmar que de la teoría a la práctica iba un gran trecho, pues incluso en Galicia, en donde el comercio cerealero no estaba tan intervenido como en Castilla ${ }^{50}$, no existía propiamente un mercado impersonal y muchas ventas aparentes no son otra cosa que acuerdos puntuales entre colonos y rentistas. Los primeros pagaban dinero buena parte de las rentas establecidas en especie, por lo que la renta ha de considerarse un factor fundamental de mercantilización de las economías campesinas, patente desde mediados del siglo XVIII. En otro orden de cosas, quizá haya que replantearse el valor de muchos libros de cuentas para el estudio de los precios agrarios, dado que pueden mezclar en un mismo ejercicio valores correspondientes a varias cosechas.

49 LABROUSSE, E.; Fluctuaciones económicas e historia social, Madrid, Tecnos, 1962.

50 LLOPIS, E. y JÉREZ, M: "El mercado de trigo en Castilla y León, 1691-1788: arbitraje espacial e intervención", Historia Agraria, 25 (2001), pp. 13-68; para análisis de los precios en los mercados locales de Galicia, GARCÍA-LOMBARDERO, J.: La agricultura y el estancamiento económico de Galicia en la España del Antiguo Régimen, Madrid, Siglo XXI, 1973, p. 62 y ss. y EIRAS ROEL, A. y USERO, R: "Los precios de los granos...". 